\title{
Numerical Study on Crack Distributions of the Single-Layer Building under Seismic Waves
}

\author{
Fenghui Dong $\mathbb{D}^{1},{ }^{1}$ Zhipeng Zhong $\mathbb{D}^{\circ}{ }^{2}$ and Jin Cheng ${ }^{3}$ \\ ${ }^{1}$ Department of Bridge Engineering, Tongji University, Shanghai 200092, China \\ ${ }^{2}$ Department of Civil Engineering, Shanxi University, Taiyuan Shanxi 030013, China \\ ${ }^{3}$ State Key Laboratory for Disaster Reduction in Civil Engineering, Tongji University, Shanghai 200092, China
}

Correspondence should be addressed to Zhipeng Zhong; zpz_2006@sxu.edu.cn

Received 20 March 2018; Revised 17 April 2018; Accepted 22 April 2018; Published 15 May 2018

Academic Editor: Changzhi Wu

Copyright (C) 2018 Fenghui Dong et al. This is an open access article distributed under the Creative Commons Attribution License, which permits unrestricted use, distribution, and reproduction in any medium, provided the original work is properly cited.

\begin{abstract}
This paper conducts a numerical simulation of the antiseismic performance for single-layer masonry structures, completes a study on crack distributions and detailed characteristics of masonry structures, and finally verifies the correctness of the numerical model by experimental tests. This paper also provides a reinforced proposal to improve the antiseismic performance of single-layer masonry structures. Results prove that the original model suffers more serious damage than the reinforced model; in particular, longitudinal cracks appear on bottoms of two longitudinal walls in the original model, while these cracks appear later in the reinforced model; a lot of cracks appear on the door hole of the original model, and no crack appears in the reinforced model till the end of seismic waves; seismic damage of walls in the reinforced model is obviously lighter than that in the original model; dynamic responses at all observed points of the reinforced masonry are obviously less than those of the original model. Strains at all positions of the reinforced model are obviously smaller than those of the original model. From macroscopic and microscopic perspectives, the computational results prove that the reinforced proposal proposed in this paper can effectively improve the antiseismic performance of the masonry structure.
\end{abstract}

\section{Introduction}

As a traditional structure form, masonry structures are widely applied in middle and small cities. Materials used by masonry structures, such as clay, sand, and stones, are local materials. Therefore, important materials including steel, cement, and timber can be saved, and engineering cost can be reduced. Masonry materials are featured by high durability and high fire resistance and do not require special technical equipment in construction [1-5]. Because of these advantages, masonry structures have been applied widely since ancient times. At present, the proportion of masonry structures in wall structures is more than $90 \%$ [6]. Masonry structures are the most utilized structure form in construction engineering. However, the traditional structure form is deficient in poor antiseismic performance, high weight, bad tension, and poor ductility. When an earthquake takes place, the structure is often damaged due to the serious displacement outside the complete wall plane [7-10]. Earthquakes have caused so many tragedies, involving house damage, wall cracks, and resultant living risks, as well as large destructions such as direct collapse, economic losses, and casualties.

Therefore, a lot of researches have been conducted on the antiseismic performance of masonry buildings at present. Zheng et al. [11] analyzed the mechanical performance of multilayer masonry structures under horizontal seismic waves, while the mechanical performance included force bearing characteristics, deformations, and damage forms as well as dynamic characteristics and antiseismic capacities of the structure under different force stages. Jia et al. [12] discussed common seismic safety problems of masonry walls, analyzed seismic damage of walls for masonry buildings in different intensity regions, obtained damage forms of houses in the intensity regions, and also proposed some suggestions on reducing seismic damage of masonry buildings. Liu and Tong [13] studied houses with a frame masonry structure, 
established a finite element model, applied seismic waves to the structure in order to conduct the elastoplasticity analysis, and analyzed changing trends of structural cracks before and after adding antiseismic walls. In order to study impacts of front longitudinal columns in walls on antiseismic performance of a multilayer masonry building, Liang et al. [14] conducted an experimental test on a masonry building using the vibration table and analyzed damage processes of this model as well as parameters including acceleration amplification coefficients and typical position strains. In order to study and prevent seismic damage of masonry structures, Liu et al. [15] used LS-DYNA to simulate collapse processes of a masonry structure, verified the correctness of the numerical model by experiments, and found weak positions in this structure under strong seismic waves, which proposed a powerful support to improve the antiseismic performance of masonry buildings. The macroelement technique for modeling the nonlinear response of masonry panels is particularly efficient and suitable for the analysis of the seismic behavior of complex walls and buildings. Therefore, Penna et al. [16] have established a macroelement model specifically developed for simulating the response of masonry walls, with possible applications in nonlinear static and dynamic analysis of masonry structures under seismic waves. Betti et al. [17] have conducted a comparison between different methods and numerical models to estimate the seismic behavior of unreinforced masonry buildings, and the model is able to predict the damaged areas and the incipient collapse mechanism, as well as the collapse load.

In these reports, detailed experimental tests and numerical simulation are mainly conducted on the antiseismic performance of multilayer masonry structures and some achievements are obtained. However, single-layer masonry structures in rural regions are rarely reported. Single-layer masonry structures are the main buildings in some regions. Residents do not have strong consciousness for antiseismic performance and prevention of these buildings. Therefore, it is very necessary to study and design the antiseismic performance. Dong et al. [18] conducted the numerical simulation of the antiseismic performance for single-layer masonry structures and proposed some reinforced measures, but failed to report the distribution, expanding processes, and detailed characteristics of building cracks. Lou et al. [19] completed the numerical simulation on the collapse of single-layer masonry structures and also conducted comparative verification between computational results and experimental results, but failed to propose any reinforced measure for improving the antiseismic performance of single-layer masonry structures. Aimed at this current status, this paper conducts the numerical simulation of the antiseismic performance for single-layer masonry structures, completes a systematic study on crack distribution and detailed characteristics of masonry structures, and finally verifies the correctness of the numerical model by experiments. This paper provides a technology support for the antiseismic performance of single-layer masonry structures.

\section{The Theoretical Basis of the Numerical Computation}

2.1. Modal Solution Theories. Modal analysis is used to determine the natural vibration characteristics of the structure, which is the natural frequency and mode shape of the structure. It is an important parameter to study the elastoplastic analysis of vertical earthquakes and also the basic premise of computing structural dynamics. Under the external load, the dynamic equation of the structural system at any moment is as follows:

$$
\left\{F_{t}\right\}+\left\{F_{D}\right\}+\left\{F_{S}\right\}=\{F\} .
$$

Among them, $\left\{F_{t}\right\},\left\{F_{D}\right\},\left\{F_{S}\right\}$ are the inertial force vector, damping force vector, and elastic force vector of the structure, respectively, and $\{F\}$ is the external load vector acting on the structure. Inertial force vector, damping force vector, and elastic force vector can be represented by $z(t)$ and its reciprocal, as follows:

$$
\begin{gathered}
\left\{F_{t}\right\}=[M]\{\ddot{z}(t)\}, \\
\left\{F_{S}\right\}=[K]\{z(t)\}, \\
\left\{F_{D}\right\}=[C]\{\dot{z}(t)\} .
\end{gathered}
$$

Among them, $[M],[C],[K]$ are the mass matrix, damping matrix, and stiffness matrix of the structure, respectively. $z(t), \dot{z}(t), \ddot{z}(t)$ are the displacement, velocity, and acceleration vectors of the structure, respectively. The dynamic equation of the structural system at any time becomes as follows if formula (2) is substituted into formula (1):

$$
[M]\{\ddot{z}(t)\}+[C]\{\dot{z}(t)\}+[K]\{z(t)\}=\{F\}
$$

When the structural system is in the free vibration state, the vibration direction of the structural system becomes

$$
[M]\{\ddot{z}(t)\}+[K]\{z(t)\}=0 .
$$

When the structural system is in the free vibration state, assuming that the displacement of the structure in free vibration is $\{z(t)\}=\{A\} \sin \omega t$, the homogeneous equations can be obtained as follows when substituting the former into formula (4):

$$
\left([K]-\omega^{2}[M]\right)\{A\}=0 .
$$

Among them, $\{A\}$ is not all 0 , so the value of the determinant of the coefficient matrix must be all 0 ; that is,

$$
\left|[K]-\omega^{2}[M]\right|=0 .
$$

According to formula (6), the mass matrix and stiffness matrix of the structural system at any time can be solved, and then the natural frequency and mode shape of the structure can be extracted.

2.2. The Constitutive Relation of the Solved Masonry. The constitutive relation of the solved masonry is one of the most important mechanical properties of the masonry structure and also the basic parameter that the model must input when solving masonry structure. At present, the constitutive relations of the solved masonry have mainly the following three kinds. 


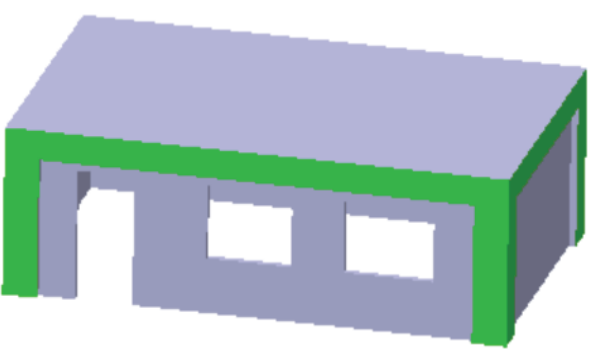

(a) Geometric model

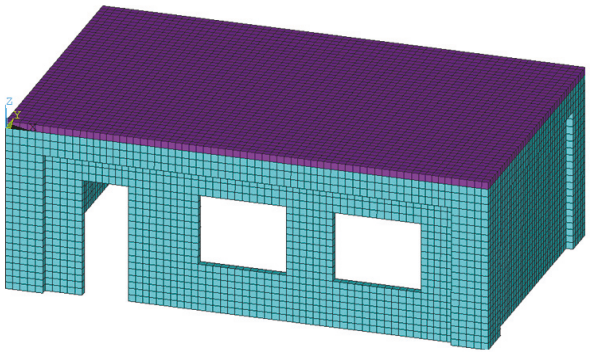

(b) Finite element model

Figure 1: Geometric model and finite element model of the masonry structure.

2.2.1. Single-Segment Constitutive Relations. The constitutive relation of masonry under a short-term load is usually determined by the axial compression test. When the stress of the masonry structure reaches a maximum value, the masonry structure will suddenly collapse under normal circumstances. According to a great deal of experience, the constitutive relation of masonry structure material is put forward as follows [20]:

$$
\varepsilon=-\frac{1}{\xi} \ln \left(1-\frac{\sigma}{f_{m}}\right) .
$$

2.2.2. Two-Segment Constitutive Relations. Based on the experimental results, Zhu and Dong give a constitutive relationship for the expression of a two-stage full-curve with ascending and descending segments [21]:

$$
\frac{\sigma}{f_{m}} \begin{cases}\frac{\varepsilon / \varepsilon_{0}}{0.2+0.8 \varepsilon / \varepsilon_{0}} & \varepsilon \leq \varepsilon_{0} \\ 1.2-0.2 \varepsilon / \varepsilon_{0} & \varepsilon>\varepsilon_{0} .\end{cases}
$$

Formula (8) is relatively simple; although it can reflect the mechanical performance of masonry structures in the stress drop stage, the formula is not derivable at $\varepsilon=\varepsilon_{0}$, indicating that the stress-strain curve is discontinuous. Zhuang conducted an experimental study of the masonry model and also gave the ascending and descending constitutive relations [22]:

$$
\frac{\sigma}{f_{m}}= \begin{cases}\frac{1.52\left(\varepsilon / \varepsilon_{0}\right)-0.279\left(\varepsilon / \varepsilon_{0}\right)^{2}}{1-0.483\left(\varepsilon / \varepsilon_{0}\right)+0.724\left(\varepsilon / \varepsilon_{0}\right)^{2}} & \varepsilon \leq \varepsilon_{0} \\ \frac{3.4\left(\varepsilon / \varepsilon_{0}\right)-1.13\left(\varepsilon / \varepsilon_{0}\right)^{2}}{1+1.4\left(\varepsilon / \varepsilon_{0}\right)-0.13\left(\varepsilon / \varepsilon_{0}\right)^{2}} & \varepsilon>\varepsilon_{0} .\end{cases}
$$

2.2.3. Polynomial Constitutive Relations. The stress-strain relation curve proposed by Turnserk and Cacovic is not only consistent with experimental results, but also smooth and continuous. Therefore, this paper selects the constitutive relation of the polynomial, and its constitutive expression is as follows [23]:

$$
\frac{\sigma}{\sigma_{\max }}=6.4\left(\frac{\varepsilon}{\varepsilon_{0}}\right)-5.4\left(\frac{\varepsilon}{\varepsilon_{0}}\right)^{1.17} .
$$

Among them, $\sigma_{\max }$ is the peak stress, and $\varepsilon_{0}$ is the strain corresponding to the peak stress.

\section{The Numerical Computation for Dynamics of Masonry Structures under Seismic Waves}

3.1. The Numerical Computation Model. In this paper, a single-layer masonry building with a relatively simple structure is selected. Related dimensions of this model are obtained through the real investigation, as shown in Figure 1(a). It is shown in this figure that doors and windows are set on the front longitudinal wall, and no hole is set on other three walls. Actual dimensions of the window hole are as follows: height is $1700 \mathrm{~mm}$ and width is $2150 \mathrm{~mm}$. Actual dimensions of the door hole are as follows: height is $2800 \mathrm{~mm}$ and width is $1320 \mathrm{~mm}$. No structural antiseismic measures including column and beam are applied to this model. In order to simplify the computation, all the surfaces of this model are smooth and even planes. Dimensions of the experimental model cannot be too large; in order to conduct the experimental verification on the correctness of the numerical model, a numerical model with scaled ratio $1: 2$ is used for the modeling. The finite element model is shown in Figure 1(b). The degree of freedom in the bottom of the masonry structure was constrained in 6 directions to simulate the actual condition. In order to realize the constraint, the degree of freedom of the element in the bottom of the finite element model was constrained. In respect of the large size of masonry models in this paper, if the finite element model of a masonry structure is established based on a discrete model, it will be limited by the computational software and computer performance. Besides, this paper is focused on the numerical simulation on a macroscopic damage type of a masonry structure, so that an integral model with easily establishing the finite element model is adopted. In this model, the integral modeling is conducted on masonry and concrete, and components are connected by co-nodes [2428]. In addition, with regard to roofs of rear houses, a clay layer will be paved on the roof board. In view of features of the clay layer, its rigidity contribution is not considered in the finite element model, its mass is uniformly distributed on the roof board, and reinforced steel bars are simulated using rod elements with dual-directional forces. Solid65 elements are used for the masonry structure. In view of tension failure and breakdown failure, element size of walls and roofs is $0.15 \mathrm{~m}$. All the materials are deemed as isotropic. Parameters of the masonry are as follows: compressive strength is $1.5 \times 10^{6} \mathrm{~Pa}$, 


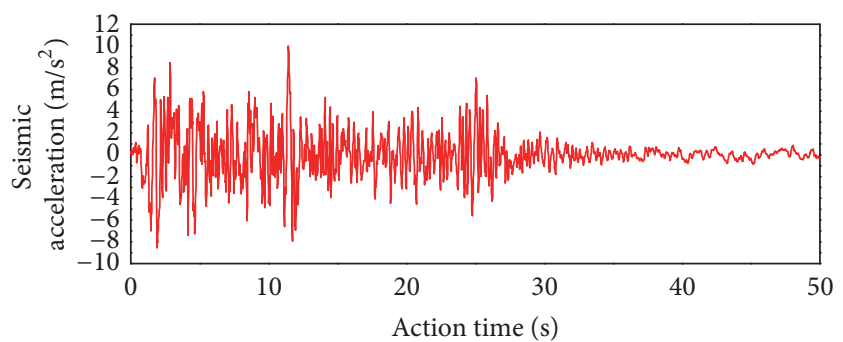

(a) Seismic waves in $X$ direction

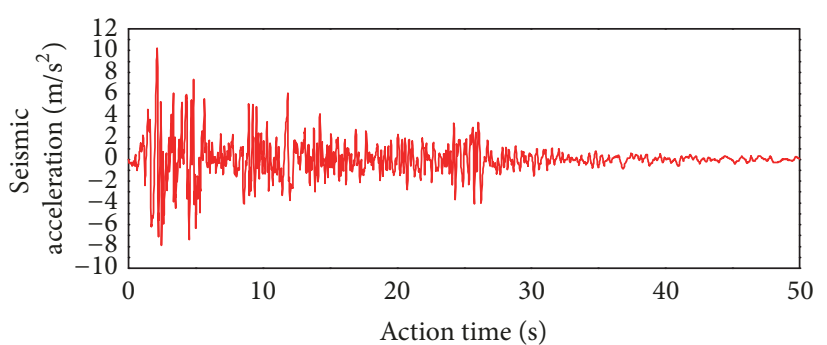

(b) Seismic waves in $Y$ direction

Figure 2: Seismic waves in time-domain in $X$ and $Y$ directions.

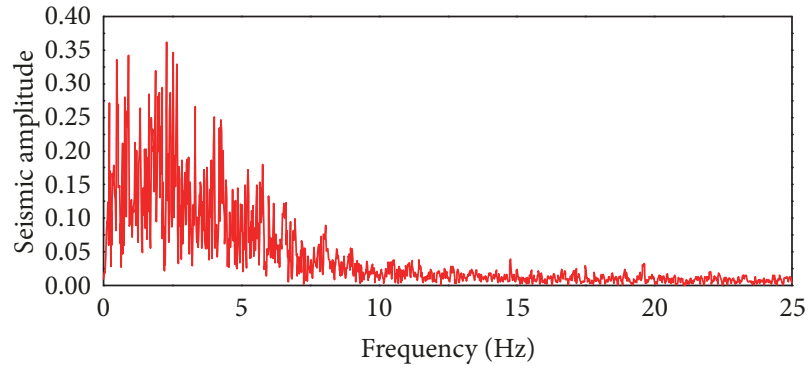

(a) Seismic waves in $X$ direction

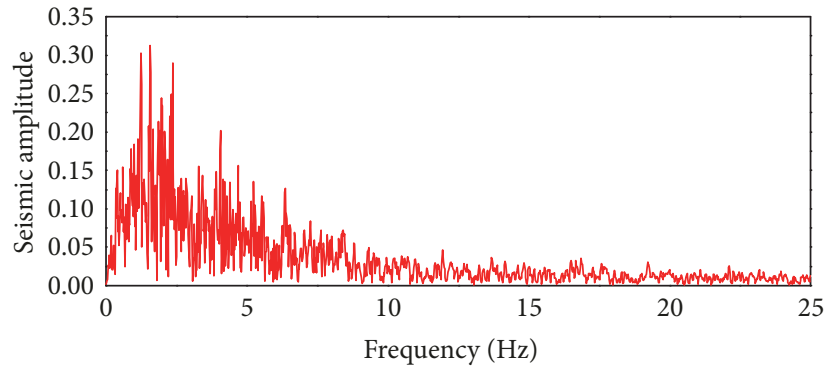

(b) Seismic waves in $Y$ direction

Figure 3: Seismic waves in frequency-domain in $X$ and $Y$ directions.

tension strength is $0.14 \times 10^{6} \mathrm{~Pa}$, elasticity modulus is $2.4 \times$ $10^{9} \mathrm{~Pa}$, Poisson's ratio is 0.15 , and density is $1900 \mathrm{~kg} / \mathrm{m}^{3}$.

The paper is mainly focused on the performance of singlelayer masonry structures under seismic waves, so seismic waves should be input into the finite element model. Local seismic waves of the single-layer masonry structure lack monitoring and recording, so EL-Centro seismic waves are used for the numerical simulation. The seismic waves are complete seismic wavers which are recorded internationally for the first time and also the seismic waves are widely used to study the seismic waves [29-34]. Typical EL-Centro waves with peak acceleration $0.3 \mathrm{~g}$ are selected as loads and applied to the $X$ direction and $Y$ direction in this model, respectively. In general, seismic energies in the $Z$ direction are very small and can be neglected. Acceleration time history of seismic waves is shown in Figure 2. It is shown in this figure that seismic waves in $X$ and $Y$ directions are not completely the same. Vibrations of the seismic waves are relatively weak after $30 \mathrm{~s}$. Data in frequency-domain can be obtained after Fourier transform for data in time-domain of EL-Centro seismic waves, as shown in Figure 3. Obviously, EL-Centro energies in the two directions are mainly concentrated within $0 \sim 10 \mathrm{~Hz}$.

During analyzing the antiseismic performance of singlelayer masonry structures, two steps should be set for the finite element model. The first step is structural responses under self-weight loads. Static problems are solved by dynamic algorithms, so monotone increasing and steady loading are adopted and self-weight loads are input in forms of data sheets in order to avoid impacts caused by sudden addition of static forces on the structure. After the first step is completed, the structure stays at a stable status under vertical static loads, and effects of the structure under static loads are introduced to the second step. The second step is the input and computation of seismic motion. In this paper, horizontal seismic motion in $X$ direction and $Y$ direction is input. Seismic motion is also input in the form of data sheets.

3.2. Natural Modals of Masonry Structures. In the modal analysis, only density, elasticity modulus, and constraint conditions play an important role, while other loads have no impact on the modal results. According to the finite element model and boundary conditions, constraint modals of the single-layer masonry structure are computed, as shown in Figure 4. It is shown in this figure that vibrations of masonry structures mainly perform bending vibrations of each wall, and no torsional vibrations are presented. The vibration shape of the masonry structure was not symmetrical because the front wall is not symmetrical. Vibration shapes at the 1st, 3rd, 4th, and 6th orders mainly performed bending vibrations of doors and windows because holes are set there and structural rigidity is weak. Vibration shapes of top plates at the 2nd and 5th orders are similar, while bending vibration directions of longitudinal walls on two sides are opposite. Natural frequencies of the single-layer masonry structure are extracted, namely, $3.5 \mathrm{~Hz}, 4.1 \mathrm{~Hz}, 4.9 \mathrm{~Hz}, 5.7 \mathrm{~Hz}, 6.5 \mathrm{~Hz}$, and $7.2 \mathrm{~Hz}$, which satisfied the distribution of modal density for large facilities. This result also indirectly verifies the effectiveness of the finite element model in this paper.

3.3. Dynamic Responses of Masonry Structures. Based on the established finite element model, its dynamic responses under seismic waves can be obtained. In order to monitor 


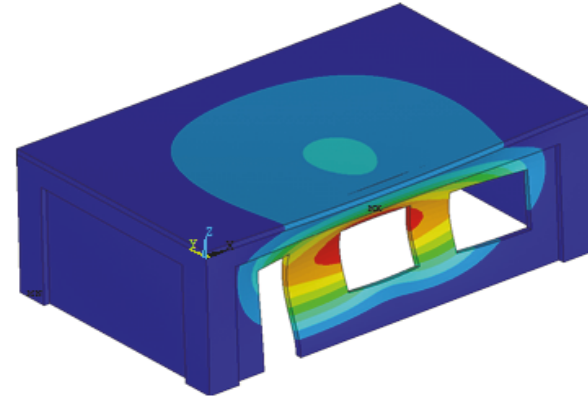

(a) First order

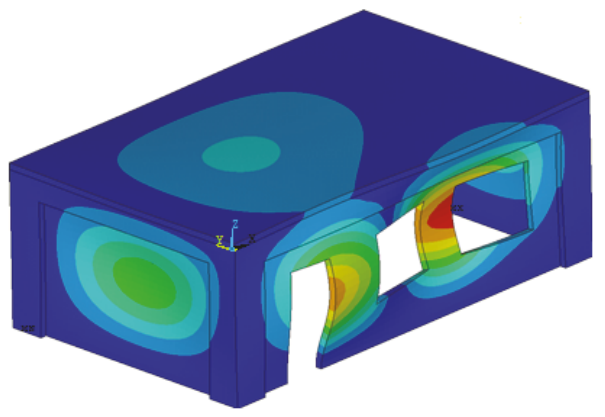

(c) Third order

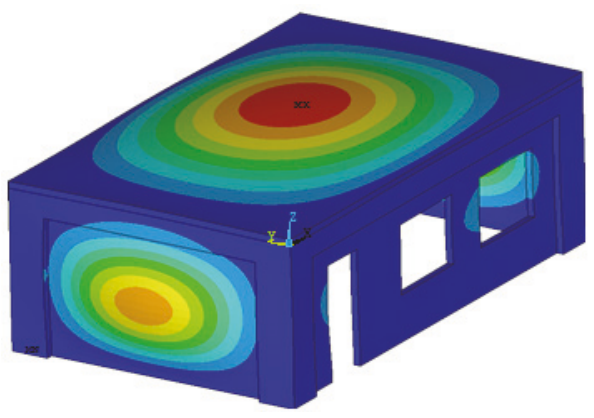

(e) Fifth order

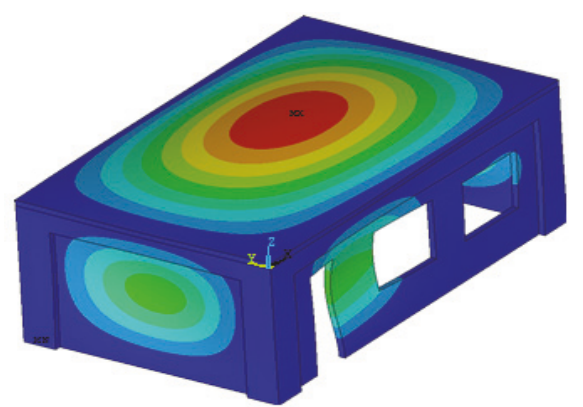

(b) Second order

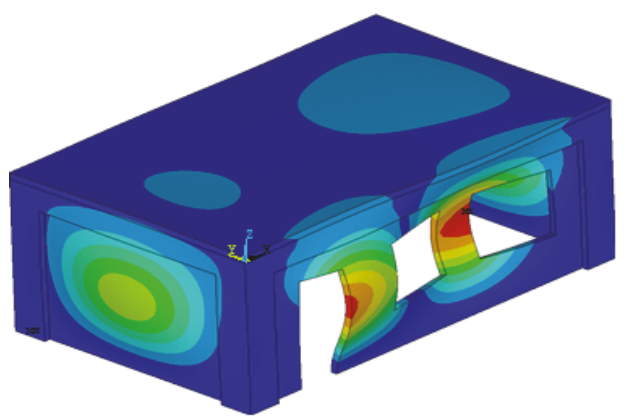

(d) Fourth order

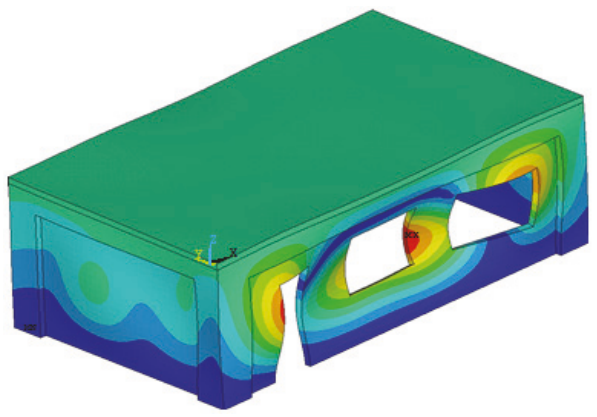

(f) Sixth order

FIGURE 4: The top six vibration shapes of the masonry structure.
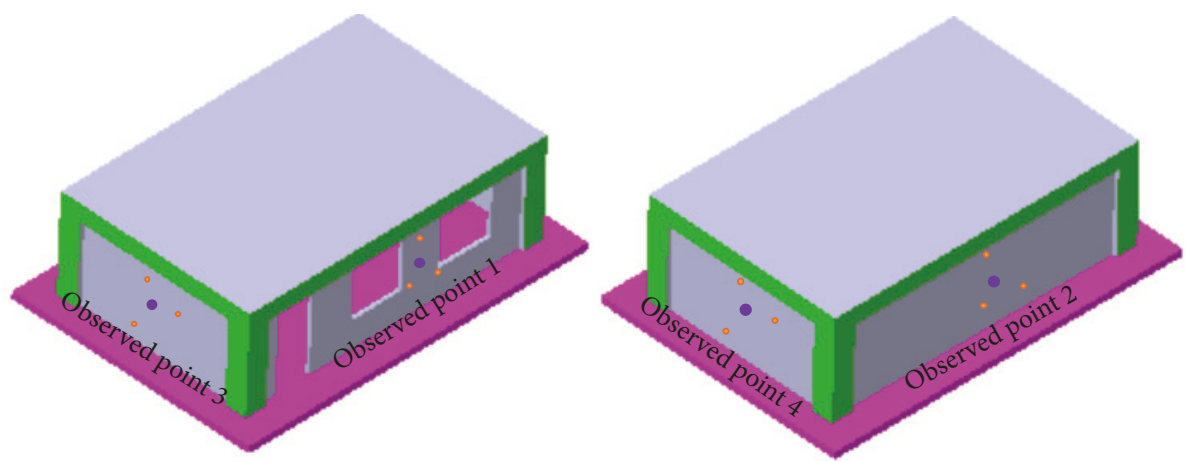

FIGURE 5: The observed points on the masonry structure.

responses of the masonry structure, 4 observed points are set at different positions of the walls, as shown in Figure 5. 3 additional points are set around each observed point and the average value of these 4 observed points is taken as a result of the observed point. Observed points 1 and 2 are used to monitor dynamic responses of front and rear longitudinal walls, and dynamic responses of left and right cross walls are monitored using observed points 3 and 4, respectively. Dynamic responses of these 4 observed points are extracted in the time-domain, as shown in Figure 6. Dynamic responses 


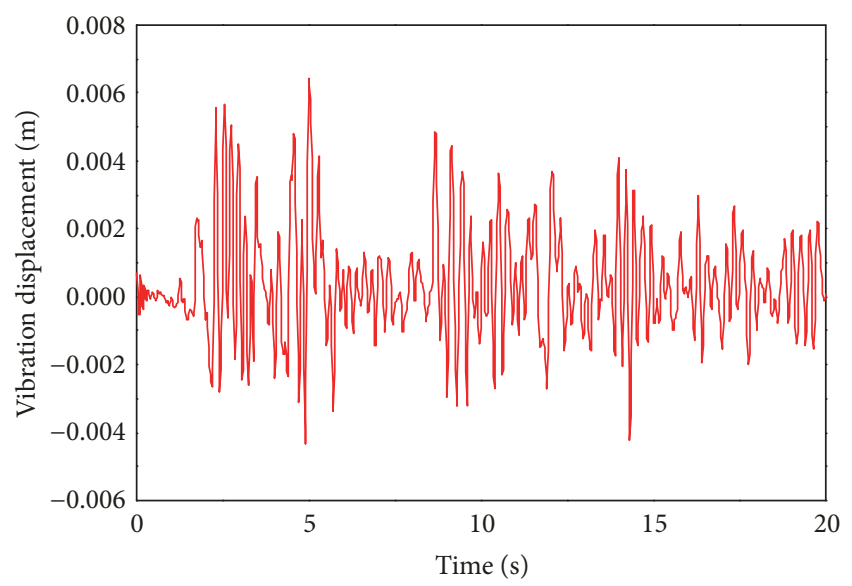

(a) Point 1

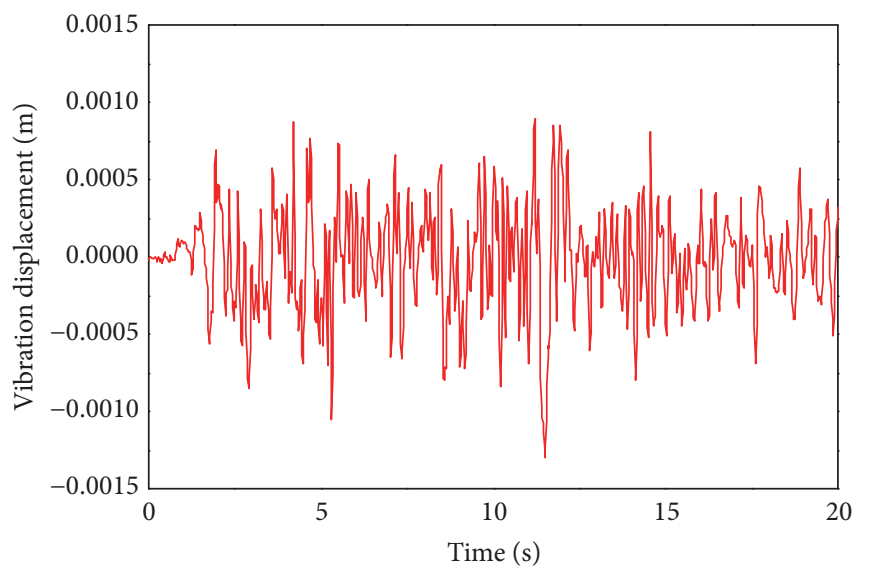

(c) Point 3

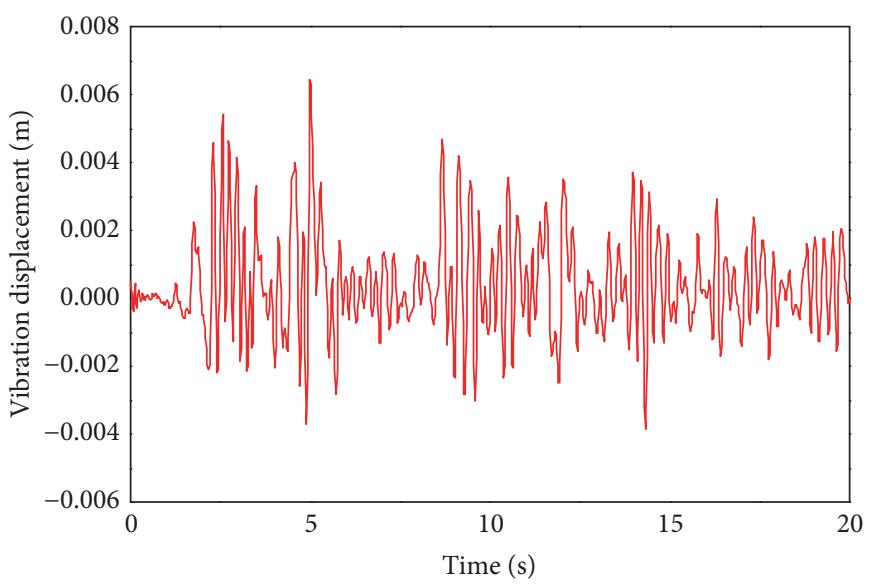

(b) Point 2

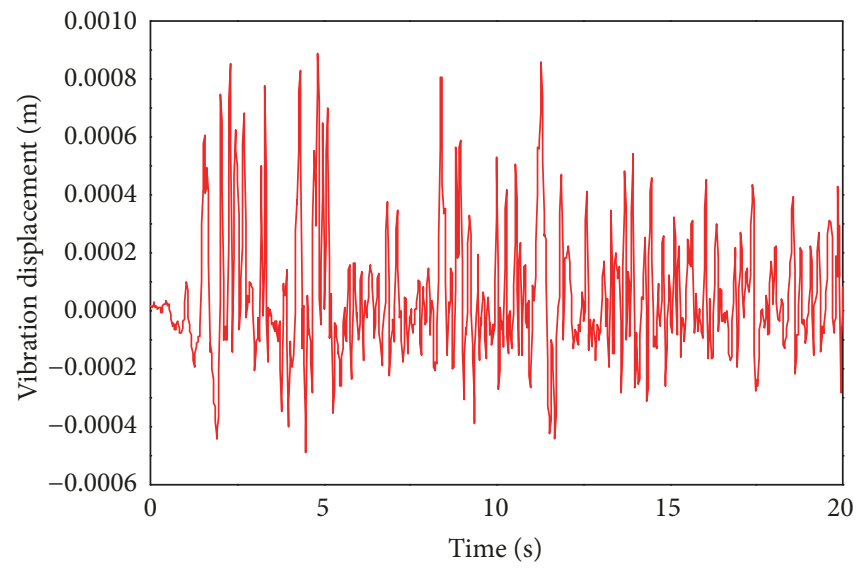

(d) Point 4

FIGURE 6: Dynamic responses of observed points on the masonry structure in time-domain.

in frequency-domain are obtained through FFT for timedomain results, as shown in Figure 7. It is shown in Figure 6 that dynamic responses of front and rear longitudinal walls are similar, and numerical results are obviously more than dynamic response results of left and right cross walls. Front and rear longitudinal walls are large in length and low in equivalent stiffness, so their dynamic responses are large under the same seismic wave. Besides, dynamic response amplitudes of front and rear longitudinal walls are at the same time points caused by local modals of two walls. Dynamic responses of left and right cross walls are obviously different, where dynamic responses of the right cross wall are smaller than those of the left cross wall because the single-layer masonry structure is not a symmetric structure, the left cross wall is close to the door hole, and the locally structural stiffness is weak. It is shown in Figure 7 that peak frequencies at different positions are similar and approach $3 \mathrm{~Hz}$, which may be attributed to fundamental frequency of the masonry structure. The computational results of modals prove that the minimum natural frequency of the masonry structure is $3.5 \mathrm{~Hz}$, and frequencies at different orders are distributed densely. Energies of each observed point are mainly concentrated within 0-6 Hz. Dynamic responses of observed points
1 and 2 are similar in time-domain, but present differences in the frequency-domain because it represents concentration of the frequency band energy and is more sensitive to small differences. However, frequency spectrum peaks of observed points 1 and 2 are basically consistent, which is also consistent with computational results in time-domain. Computational results of observed points 3 and 4 are obviously less than those of observed points 1 and 2 in frequency-domain. Spectrum peak regions are wide and dual-peak regions are obvious. The reason may be that stiffness difference between left and right cross walls is obvious, and local torsional effects are generated to the masonry structure.

3.4. Crack Distributions of Masonry Structures. Researches on crack propagation and damage process of a masonry structure under seismic waves are very important for studying the weak parts of the structure as well as the rescue work. In finite element analysis, cracks are mainly treated by a discrete crack model and a diffuse crack model. In the discrete crack treatment, cracks are formed due to fracture between elements. The method is similar to the discrete element method and established based on noncontinuous geometric conditions. However, the modeling is complicated, 


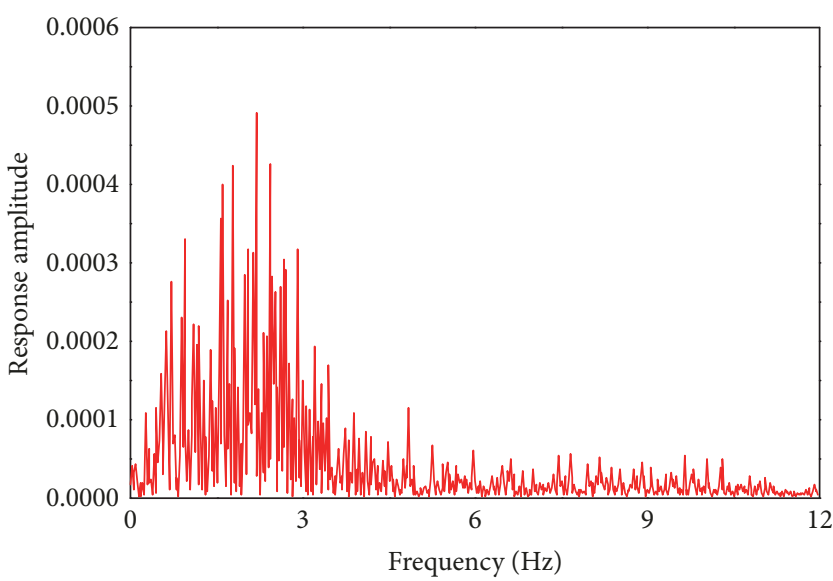

(a) Point 1

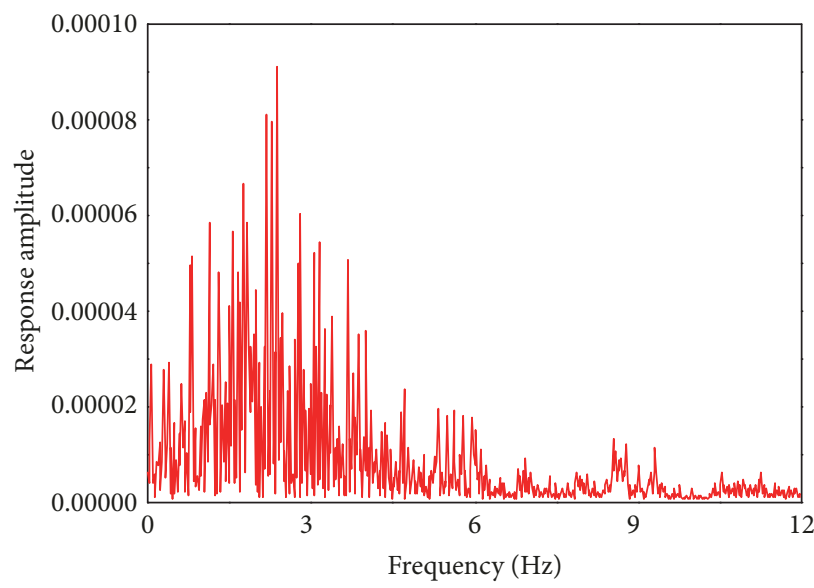

(c) Point 3

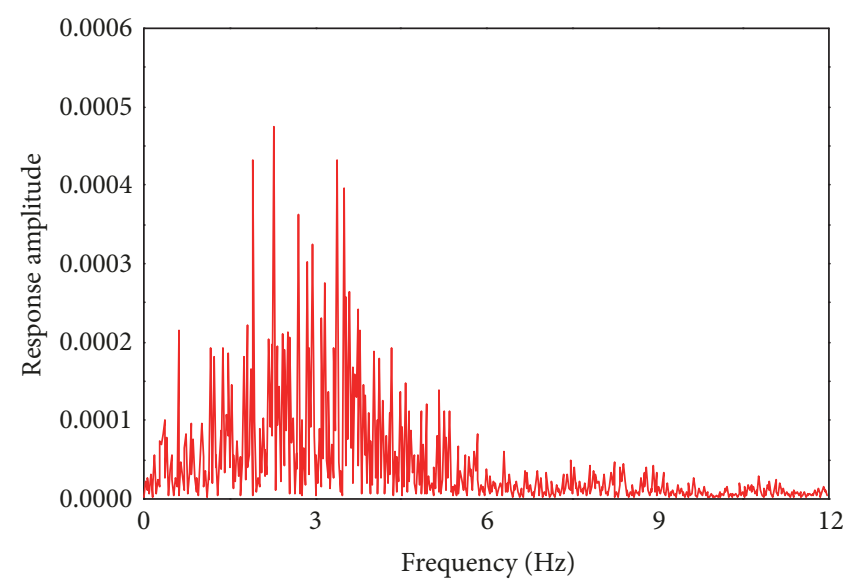

(b) Point 2

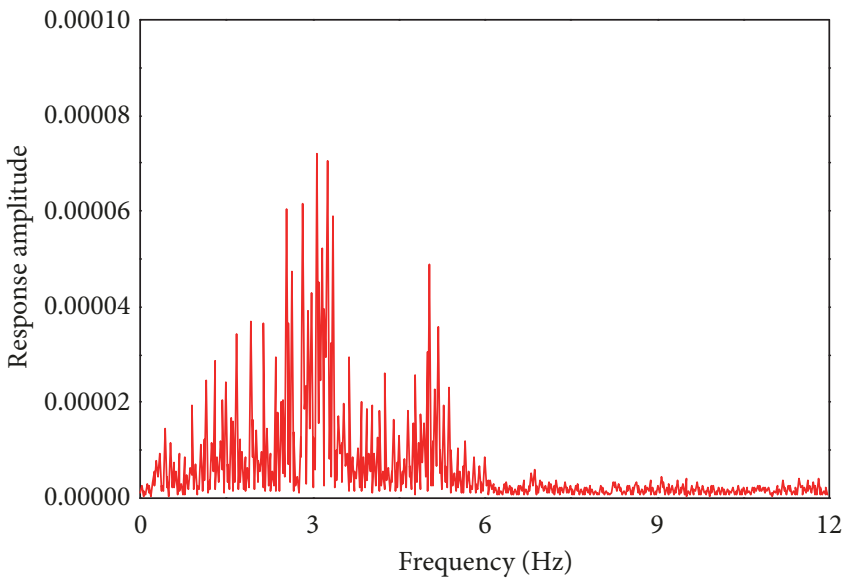

(d) Point 4

Figure 7: Dynamic responses of observed points on the masonry structure in frequency-domain.

so this method is not suitable for the numerical simulation of large structures. In diffuse crack treatment, cracks are formed on elements based on material constitution, where geometric continuity of this model is still maintained after crack formation. The modeling of the diffuse crack treatment is simple and correct results can be obtained through rational selecting material and constitutive models. Therefore, this paper selects the diffuse crack model to simulate the crack propagation of single-layer masonry structures.

Figure 8 presents the crack propagation of the singlelayer masonry structure under $20 \mathrm{~s}$ seismic waves. Cracks start taking place since the moment $1.68 \mathrm{~s}$ of EL-Centro seismic waves. With continuous affecting of seismic waves, the cracks expand continuously till the moment $5.98 \mathrm{~s}$ when rear walls and walls of windows and door boundaries are completely penetrated. During $5.98 \mathrm{~s} \sim 20 \mathrm{~s}$, derivation of cracks is stopped, while the cracks get increasingly wider. At this time, the rear wall is completely destroyed. Development processes of cracks are as follows: at $1.68 \mathrm{~s}$, cracks based on tension damage begin taking place on the door, upper left corner of windows, turning corners of walls, and lower right corner of the door; as a result, the corner of the window and door will be damaged firstly because the stiffness in these positions is relatively weak as the space structure in these positions is discontinuous; at $1.98 \mathrm{~s}$, cracks around doors and windows expand continuously, a lot of cracks appear on the bottom of front longitudinal walls, and cracks also appear on the bottom of rear longitudinal walls; at $2.32 \mathrm{~s}$, secondary cracks appear on bottoms of the front and rear longitudinal walls, cracks are continuously widened, and large cracks appear at the middle part of rear longitudinal walls and pass throughout the longitudinal direction of masonry structures; at $5.98 \mathrm{~s}$, cracks pass through doors and windows of the front longitudinal wall, and cracks at the middle part of rear longitudinal walls develop downwards. As shown in Figure 8, during $5.98 \mathrm{~s}-20 \mathrm{~s}$, cracks stop their external expansion and become increasingly wider, secondary cracks and third cracks appear at original crack positions in succession. At this moment, the walls are damaged already and may collapse under seismic waves. Therefore, if the time is more than $20 \mathrm{~s}$, the computational results will not have an obvious difference compared with those results within $20 \mathrm{~s}$.

3.5. Damage Analysis on Masonry Structures. Tension damage will easily appear in a masonry structure. In general, the damage is caused by cracks of masonry structures. It 


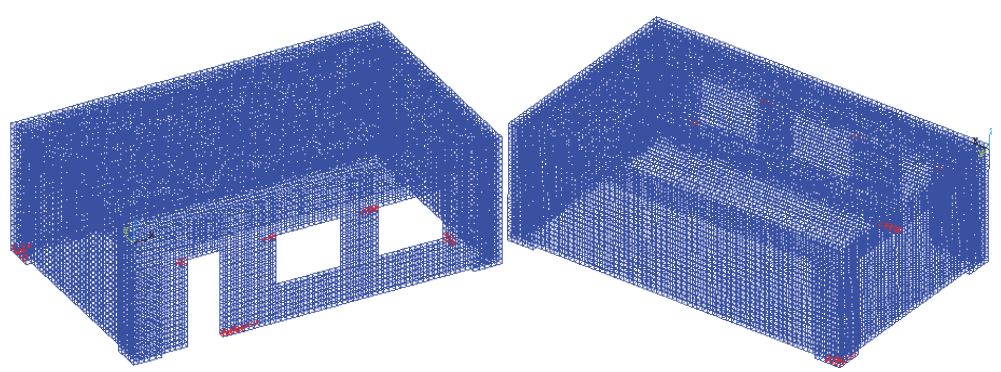

(a) Time $=1.68 \mathrm{~s}$

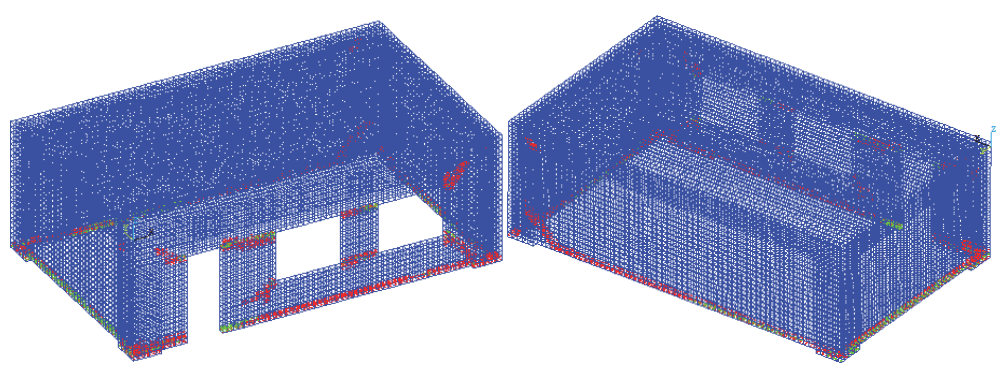

(b) Time $=1.98 \mathrm{~s}$

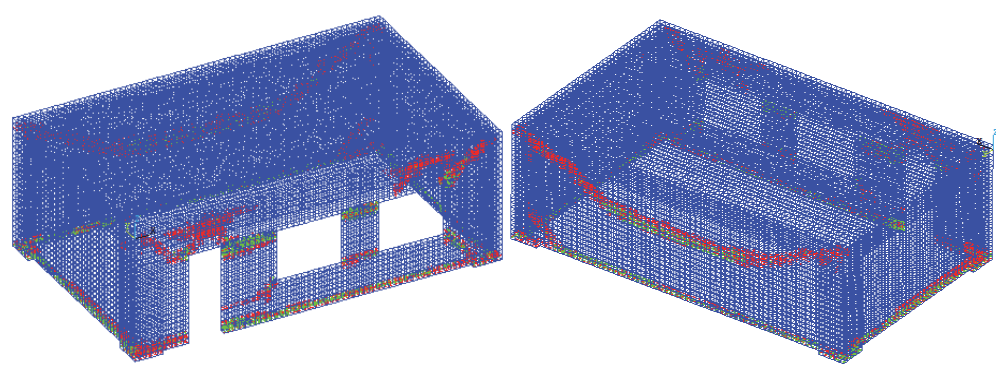

(c) Time $=2.32 \mathrm{~s}$

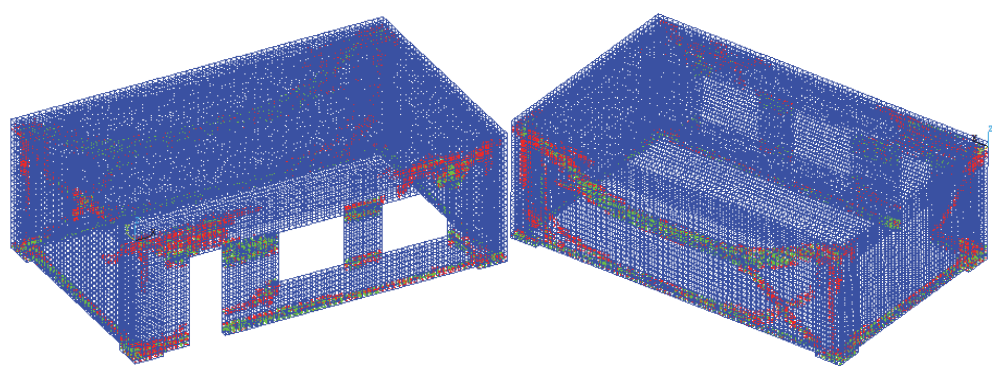

(d) Time $=5.98 \mathrm{~s}$

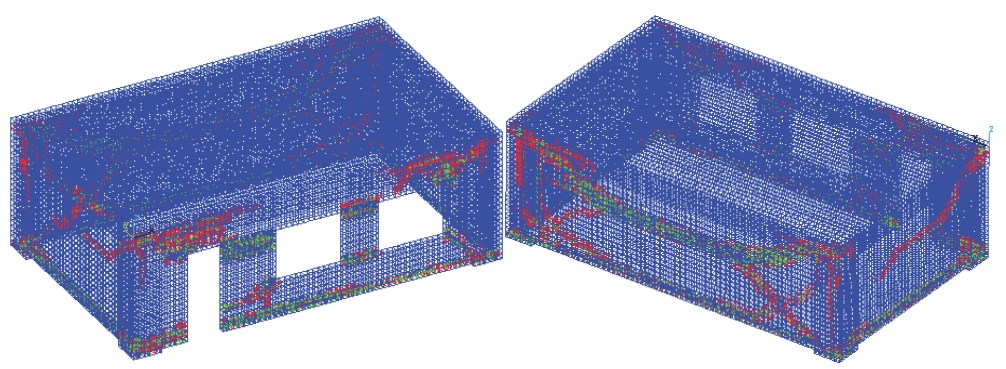

(e) Time $=20.0 \mathrm{~s}$

FIGURE 8: Crack distributions of the original masonry structure at different moments. 
is shown in Figure 8 that cracks start appearing on the masonry structure since $1.68 \mathrm{~s}$, but the cracks are very small. At this moment, the masonry structure basically suffers no damage, as shown in Figure 9(a). At 1.98 s, some cracks take place on the front longitudinal wall and the bottom, so a little of damage appears around doors and windows of the masonry structure. At $2.32 \mathrm{~s}$, the masonry structure begins suffering serious damage, especially the door, window, and bottom. When the loading of seismic waves continues to $5.98 \mathrm{~s}$, the walls begin suffering large-region damage. A region at the middle part of rear longitudinal wall is nearly free of damage. According to crack distributions in Figure 8, we can find no obvious crack appearing in this region. At $5.98 s-20.0 s$, damage distributions do not change obviously, the damage-free region is gradually reduced, and the damage shapes are kept consistent. The analyzed results prove that the distribution of cracks and damage on front and rear longitudinal walls is basically consistent; only a few of cracks appear on left and right cross walls, but the damage is serious. The reason is that a lot of cracks appear on the bottom of masonry structures, which seriously affects the stability of the masonry foundation and further intensify damage and instability of the upper parts of cross walls.

\section{Experimental Verification of the Computational Model}

Boundary conditions and parameters of a simulation model are very complicated, so its correctness should be verified by experimental tests. Before a vibration table test is conducted, a masonry structure should be made. Mortar joints should be plump during the wall masonry. Constructional columns are poured after the wall is built. During the wall is being built, the masonry toothing is built at constructional columns, so co-work and coordinated deformation between constructional columns and walls can be achieved. A reinforcement cage is preset at the constructional column. Reinforcement of the constructional column is shown in Figure 10. The vibration table is $5.0 \mathrm{~m} \times 5.0 \mathrm{~m}$, and it is a three-way vibration table with electrohydraulic servo. Parameters of the vibration table are as follows: the maximum bearing force is $30 \mathrm{t}$, maximum overturning moment is $75 \mathrm{t} \cdot \mathrm{m}$, maximum horizontal acceleration is $10.0 \mathrm{~m} / \mathrm{s}^{2}$, vertical maximum acceleration is $7.0 \mathrm{~m} / \mathrm{s}^{2}$, maximum velocity is $0.60 \mathrm{~m} / \mathrm{s}$ for single-way input, maximum velocity is $0.30 \mathrm{~m} / \mathrm{s}$ for three-way input, horizontal maximum displacement is $\pm 0.08 \mathrm{~m}$, and vertical maximum displacement is $\pm 0.05 \mathrm{~m}$. The vibration table can simulate sine waves, sine frequency sweeping waves, recorded seismic waves, and artificial seismic waves. Experimental data is collected by a SigLab data collector. FBA-11 force balance sensor is used as the acceleration sensor, with the pass band $0-80 \mathrm{~Hz}$ and sensitivity $2.50 \mathrm{~V} / 1.0 \mathrm{~g}$. Main parameters of the sensor are listed as follows: range is $\pm 10 \mathrm{~cm}$, and resolution ratio is $0.2 \mathrm{~mm}$. The range may be more than the limit, while other parameters basically satisfy measurement requirements. In order to compare numerical simulation results, tested points should be arranged according to Figure 5. Experimental data is compared with the simulation results, as shown in Figure 11.
It is shown in this figure that changing trends between numerical simulation and experimental test are basically consistent. Values of experimental tests are less than those of the numerical simulation because the numerical simulation is an ideal condition and has relatively ideal parameters, but parameters of the actual masonry structure are very complicated, while own damp of the experimental table will bring some attenuation effects on seismic waves. Nevertheless, the maximum relative errors between numerical simulation and experimental test are not more than $5 \%$, which fully proves that the numerical model in this paper is reliable and can be used to replace the experimental test.

\section{Dynamic Responses of the Reinforced Masonry under Seismic Waves}

5.1. Reinforced Proposal and Model. Walls of the model are reinforced using polystyrene packing tapes, the masonry toothing is set at joints and supporting positions of walls, and two supporting columns are set in the masonry space, as shown in Figure 12(a). The reinforced technology is simple and economic to improve the antiseismic performance. Packing tapes are simulated by cable elements which only bear axial forces, and components are connected by co-nodes. Solid elements are adopted for the established model. Contact is defined between packing tapes and walls. Tie constraints are applied to joints between components. Finally, the finite element model of the reinforced masonry is obtained, as shown in Figure 12(b).

5.2. Crack Distributions of the Reinforced Masonry. Crack analysis is conducted on the reinforced masonry. Analyzed results are compared with the original model, as shown in Figure 13. Damage positions of two kinds of models are basically consistent. Seismic damage is mainly concentrated on door and window holes, bottom and rear longitudinal walls. However, the original model suffers more seismic damage than the reinforced model. In particular, longitudinal cracks appear on bottoms of two longitudinal walls of the original model, while these cracks appear later in the reinforced model. A lot of cracks appear on the door hole of the original model, and no crack appears in the reinforced model till the end of seismic waves. A lot of cracks appear on upper middle parts of the rear longitudinal walls in two kinds of models, indicating that rear longitudinal walls are a weak part in the structure. Stress concentration takes place at this part to cause some cracks easily, so cracks expand further with the increased peaks of input seismic waves. However, seismic damage of two walls in the reinforced model is obviously lighter than that in the original model. To a certain extent, we can believe that packing tapes and supporting structures can improve the integrity of walls and delay propagation of wall cracks.

5.3. Dynamic Responses of the Reinforced Masonry. In order to present the reinforced effects visually, dynamic responses at observed points in Figure 5 are extracted and compared with results in the original model, as shown in Figure 14. It is shown in this figure that dynamic responses at all observed 


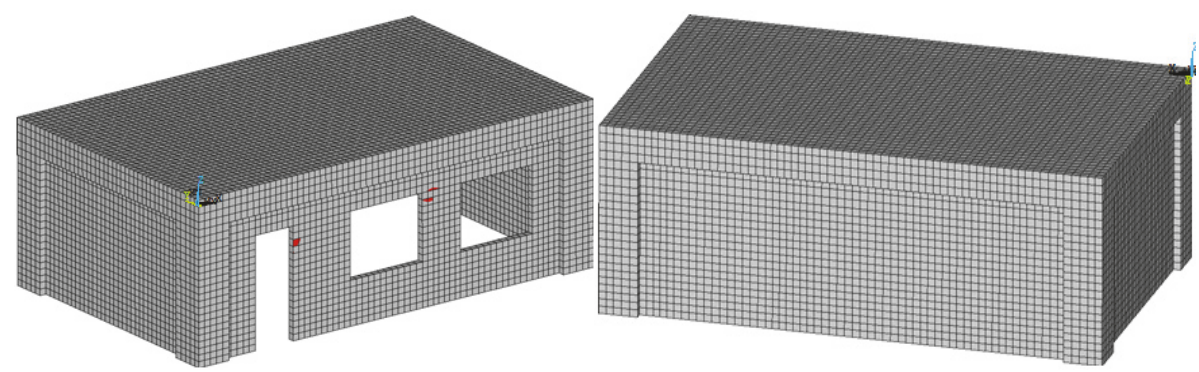

(a) Time $=1.68 \mathrm{~s}$

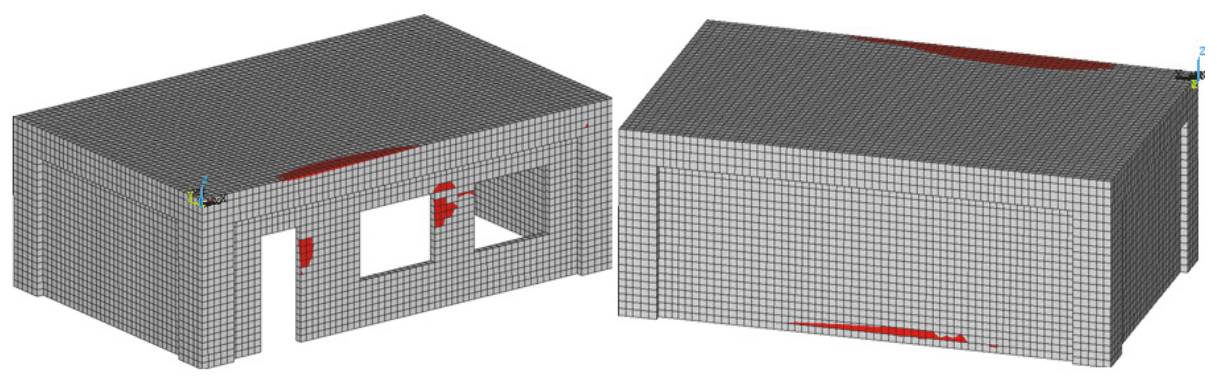

(b) Time $=1.98 \mathrm{~s}$

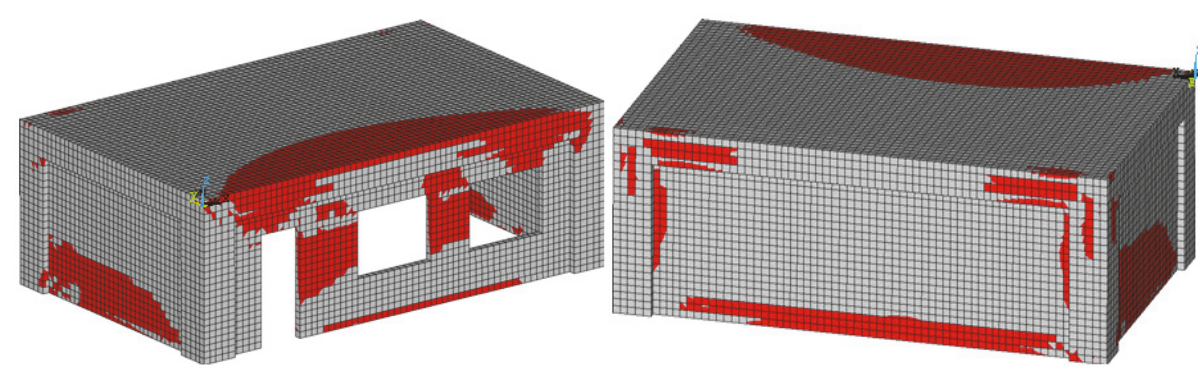

(c) Time $=2.32 \mathrm{~s}$

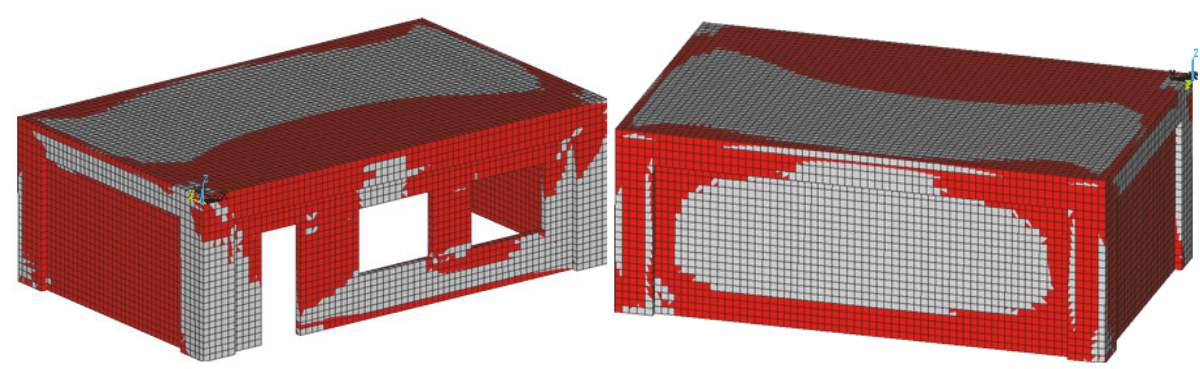

(d) Time $=5.98 \mathrm{~s}$

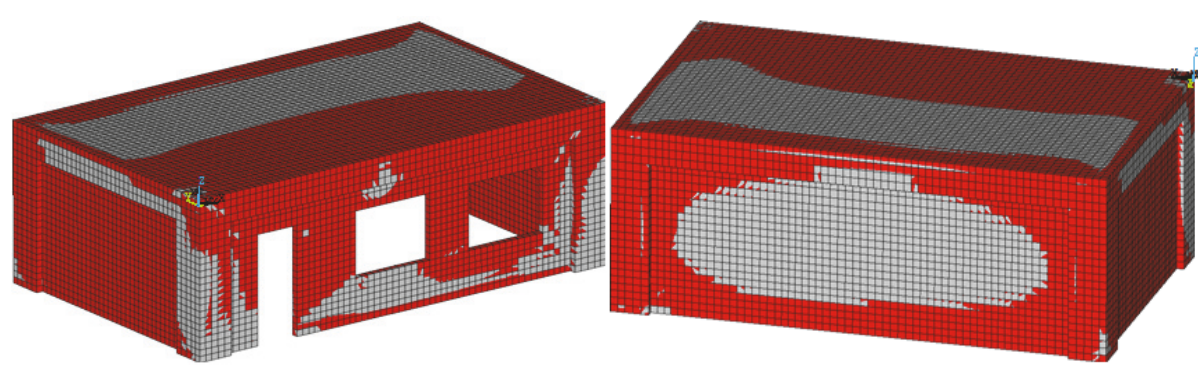

(e) Time $=20.0 \mathrm{~s}$

FiguRE 9: Damage distributions of the original masonry structure at different moments. 


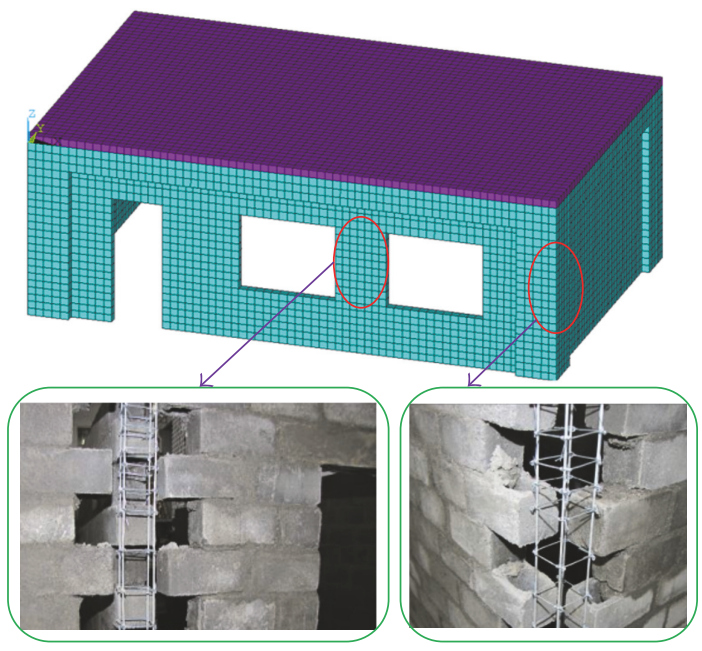

FIGURE 10: Experimental test on the dynamic response of the masonry structure.

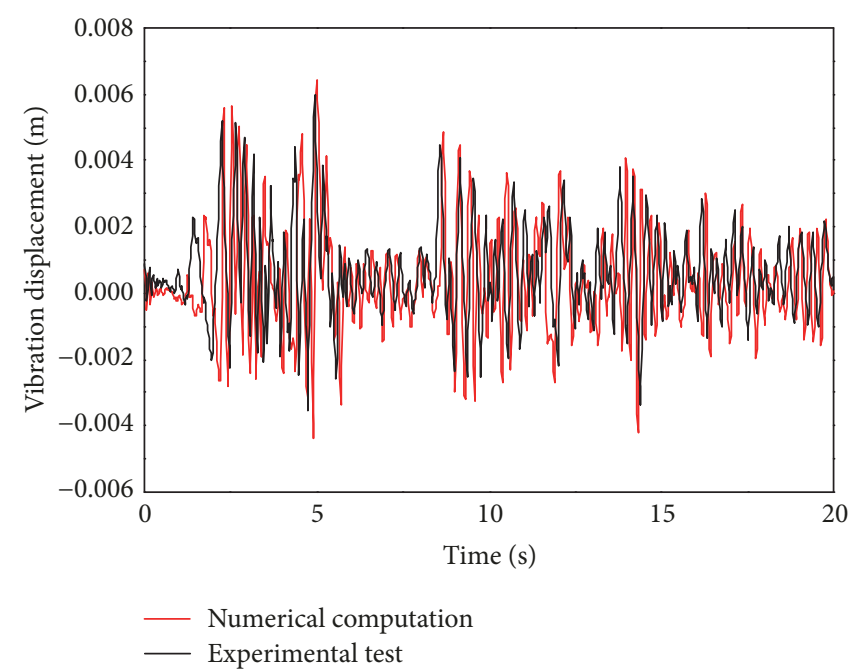

(a) Point 1

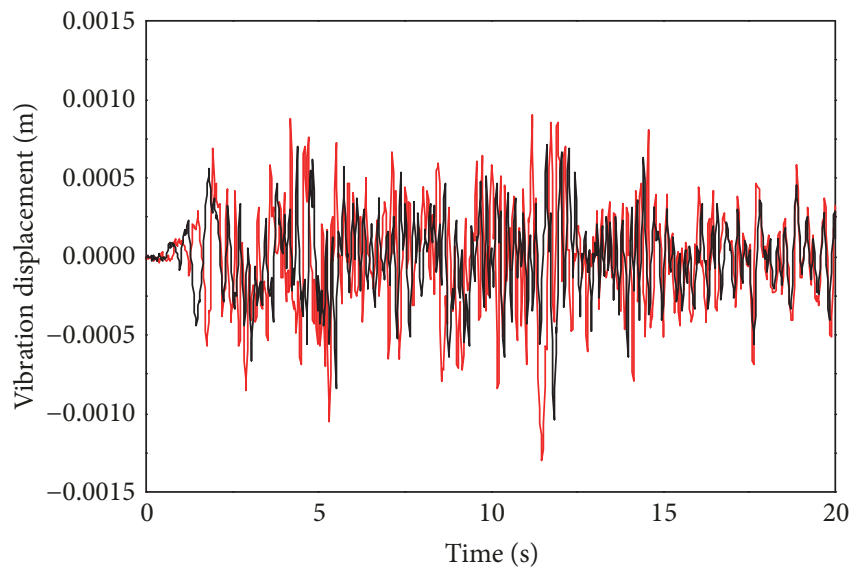

- Numerical computation

— Experimental test

(c) Point 3

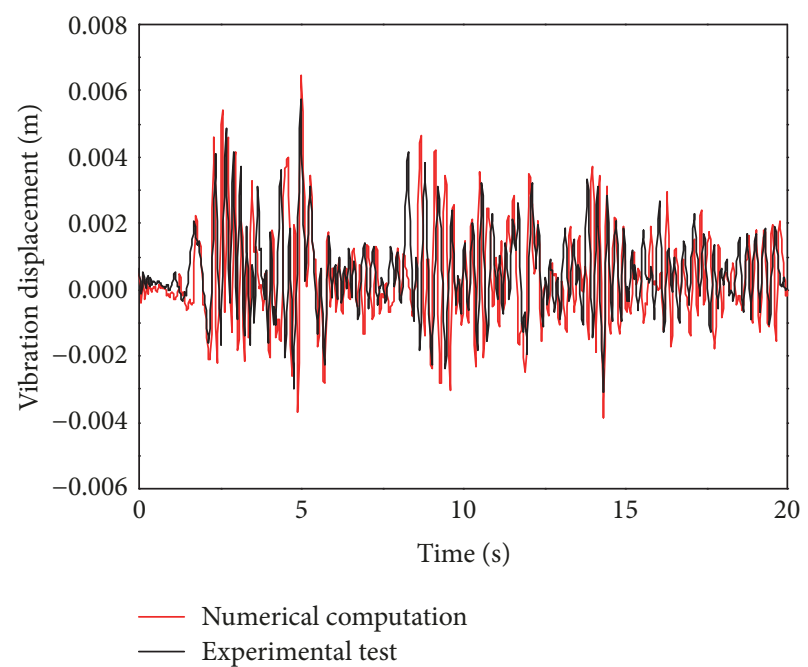

(b) Point 2

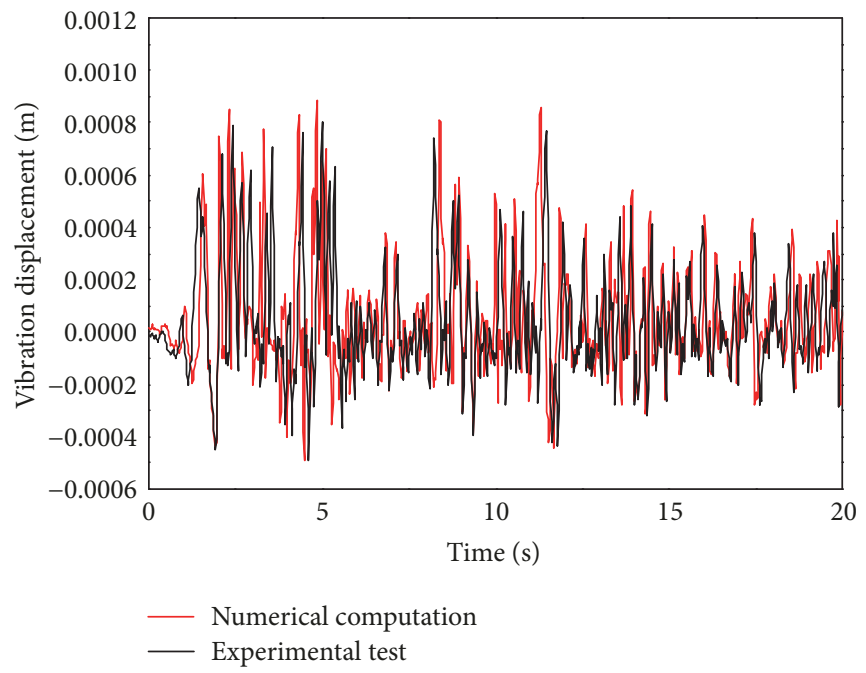

(d) Point 4

FIGURE 11: Dynamic responses of tested points on the masonry structure in time-domain. 


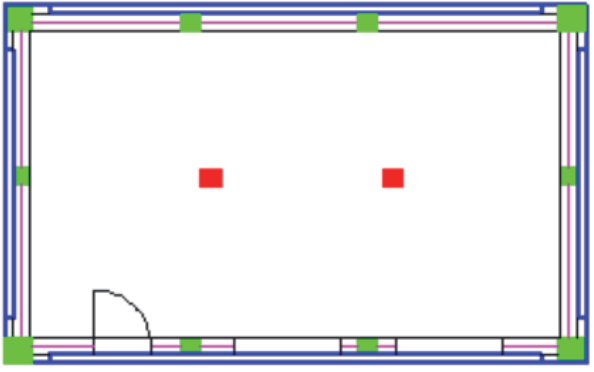

(a) Reinforced proposal

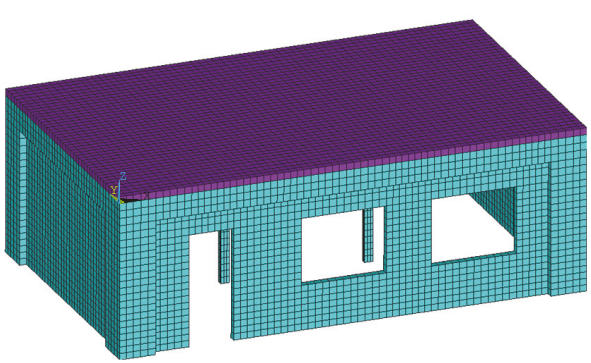

(b) Finite element model of the reinforced masonry

FIGURE 12: Reinforced proposal and finite element model of the masonry structure.

points of the reinforced masonry are obviously less than those of the original model. Peak responses of two kinds of models appear basically at the same moments. Macroscopically, the result proves that the antiseismic performance of the masonry can be effectively improved by the reinforced proposal. Microscopically, equivalent stress and strain at observed points of two kinds of models are further computed, as shown in Figure 15. It is shown in this figure that, under the same equivalent stress, equivalent strains of the reinforced masonry are obviously less than those of the original model. In particular, when the equivalent stress is $1.7 \mathrm{MPa}$, the equivalent strain of the reinforced masonry is only half that of the original model. From macroscopic and microscopic perspectives, the results prove that the reinforced proposal proposed in this paper can effectively improve the antiseismic performance of the masonry structure.

Strains of two kinds of models under different seismic waves are computed, as shown in Figure 16. It is shown in this figure that strains are small when the seismic wave amplitude is less than $0.2 \mathrm{~g}$; strains are increased rapidly after $0.2 \mathrm{~g}$ because the masonry structure stays at an elastic deformation stage when the seismic wave amplitude is less than $0.2 \mathrm{~g}$ and the structure stays at a cracking stage when the value is more than $0.2 \mathrm{~g}$. In the original model, positions between doors and windows have the largest strains, lower left corner and right corner of the left window rank the second, and positions near the right window have the smallest strains. This result is consistent with actual situations as positions between doors and windows must bear dual effects of doors and windows, so that the overall stiffness is small. Strain sequence of key positions in the reinforced model is consistent with that of the original model, but the increased strain magnitude of the reinforced model is larger when the seismic wave amplitude is more than $0.2 \mathrm{~g}$. Besides, strains at all positions of the reinforced model are obviously smaller than those of the original model, which also proves that the reinforced proposal proposed in this paper can reduce strains of walls and improve the antiseismic performance.

\section{Conclusions}

This paper conducts a numerical simulation of the antiseismic performance for single-layer masonry structures, completes a study on crack distributions and detailed characteristics of masonry structures, and finally verifies the correctness of the numerical model by experimental tests. This paper also provides a reinforced proposal to improve the antiseismic performance of single-layer masonry structures, and the following conclusions can be achieved:

(1) Dynamic responses of front and rear longitudinal walls are similar, and numerical results are obviously more than dynamic responses of left and right cross walls. Peak frequencies at different positions are similar and approach $3 \mathrm{~Hz}$. Energies of each observed point are concentrated within $0-6 \mathrm{~Hz}$. Spectrum peak regions are wide and dual-peak regions are obvious.

(2) Cracks start taking place since the moment $1.68 \mathrm{~s}$. With continuous affecting of seismic waves, the cracks expand continuously till the moment $5.98 \mathrm{~s}$ when rear walls, windows, and door boundaries are completely penetrated. During $5.98 \mathrm{~s} \sim 20 \mathrm{~s}$, cracks stop their external propagation and become increasingly wider, and secondary cracks and third cracks appear at original crack positions in succession. At this moment, the walls are damaged already and may collapse under seismic waves.

(3) The original model suffers more seismic damage than the reinforced model. In particular, longitudinal cracks appear on bottoms of two longitudinal walls of the original model, while these cracks appear later in the reinforced model. A lot of cracks appear on the door hole of the original model, and no crack appears in the reinforced model till the end of seismic waves. Also, a lot of cracks appear on upper middle parts of the rear longitudinal walls in two kinds of models, indicating that rear longitudinal walls are a weak part in the structure. Seismic damage of walls in the reinforced model is obviously lighter than that in the original model. We can believe that packing tapes and supporting structures can improve the integrity of walls and delay propagation of wall cracks.

(4) Dynamic responses at all observed points of the reinforced masonry are obviously less than those of the original model. Strains at all positions of the reinforced model are obviously smaller than those of the original model. From macroscopic and microscopic perspectives, the results prove that the reinforced proposal proposed in this paper 


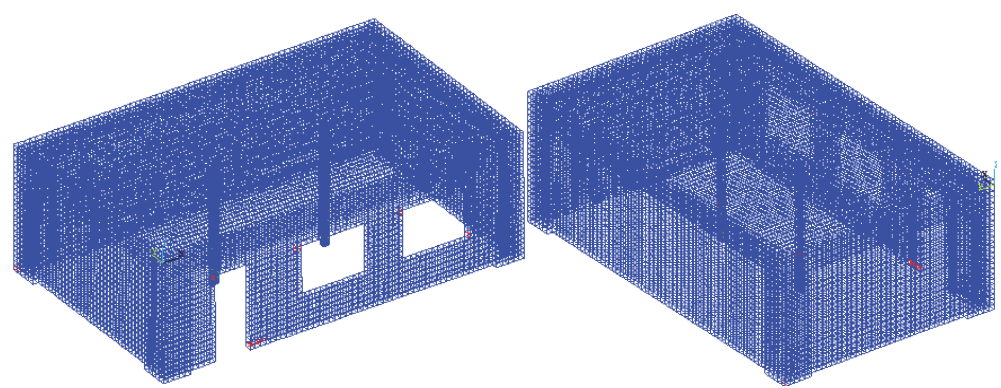

(a) Time $=1.68 \mathrm{~s}$

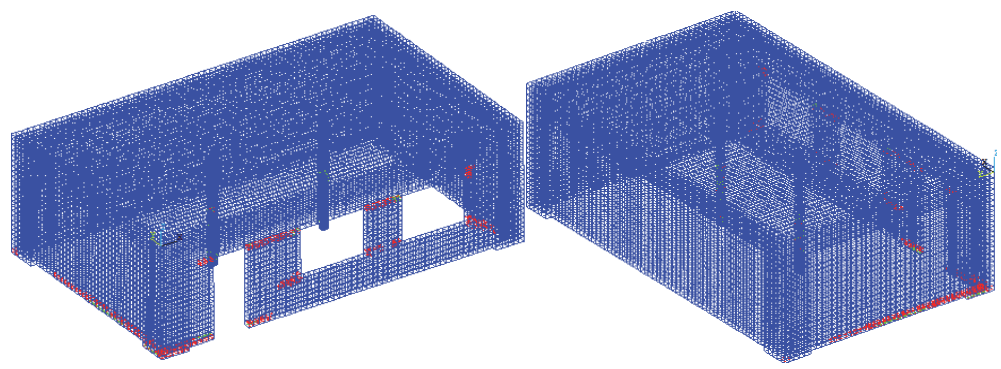

(b) Time $=1.98 \mathrm{~s}$

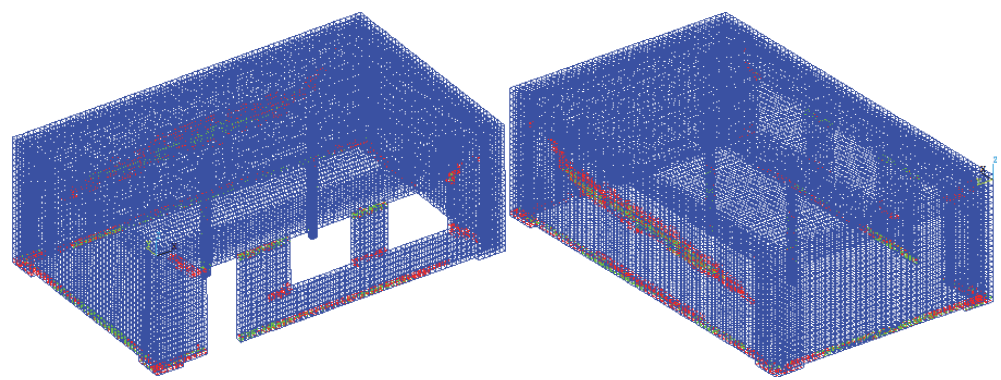

(c) Time $=2.32 \mathrm{~s}$

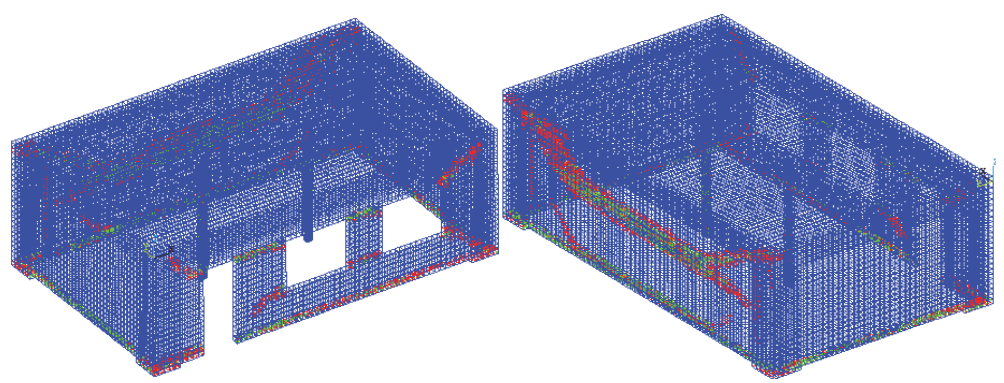

(d) Time $=5.98 \mathrm{~s}$

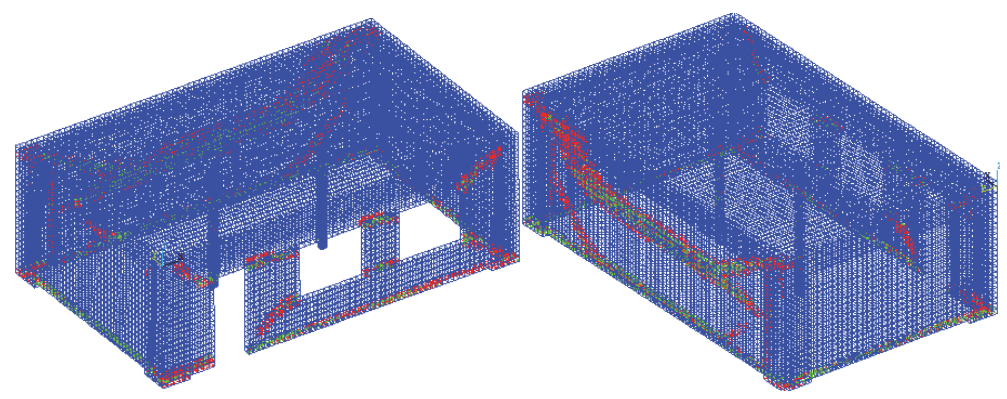

(e) Time $=20.0 \mathrm{~s}$

FIGURE 13: Crack distributions of the reinforced masonry structure at different moments. 

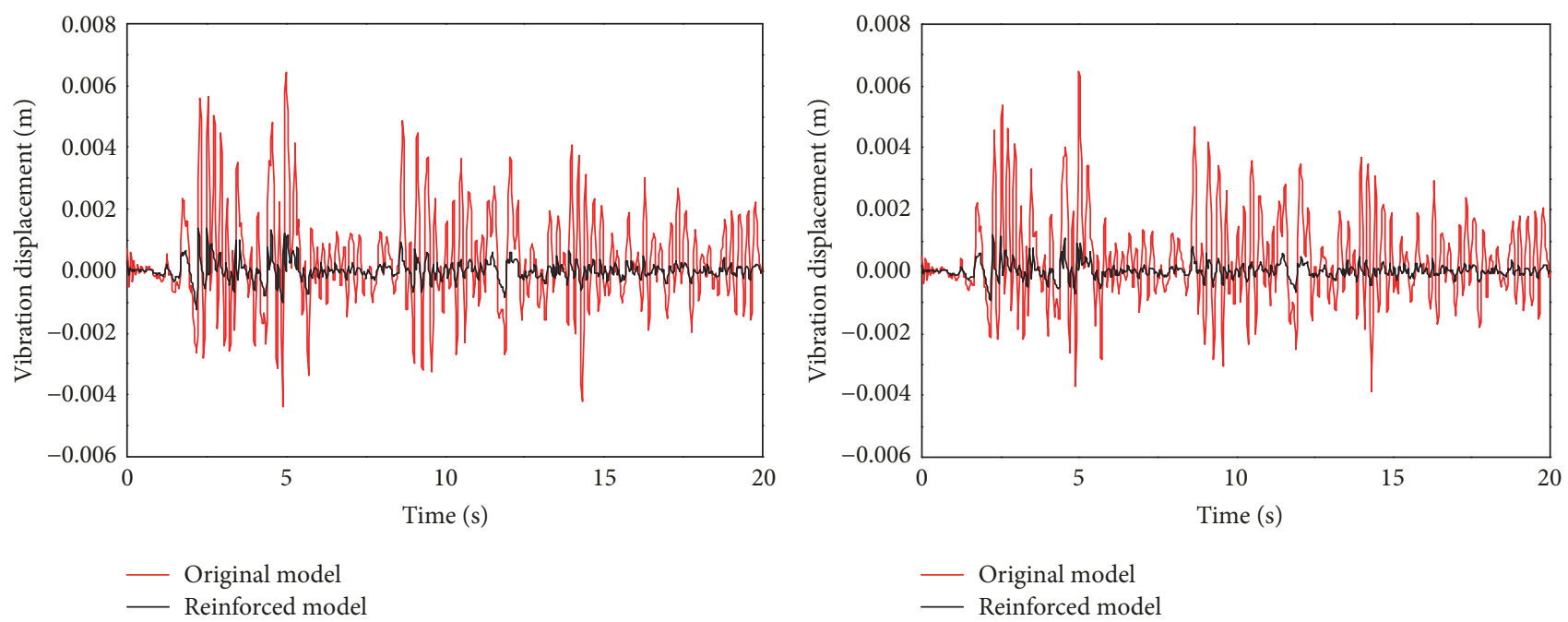

(a) Point 1

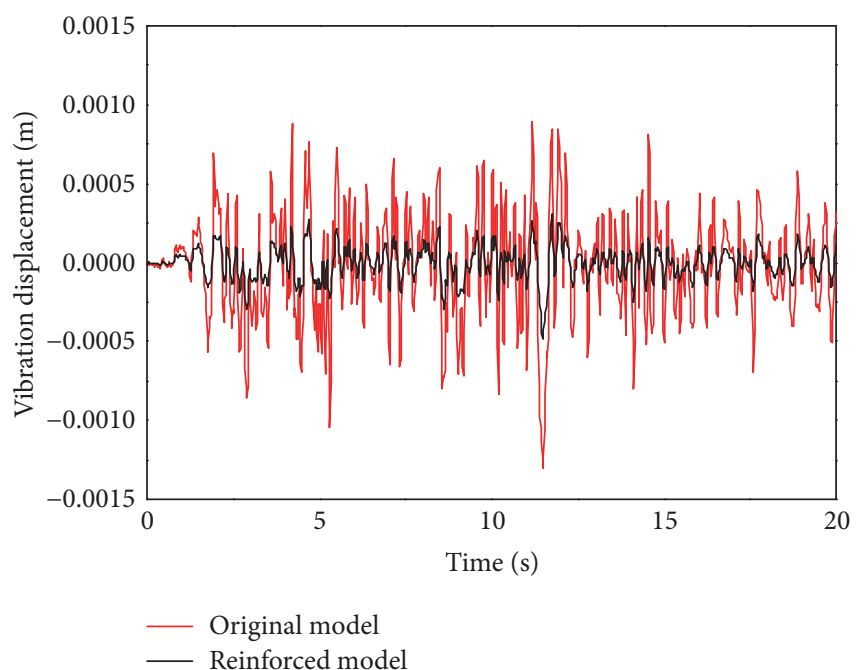

(c) Point 3 (b) Point 2

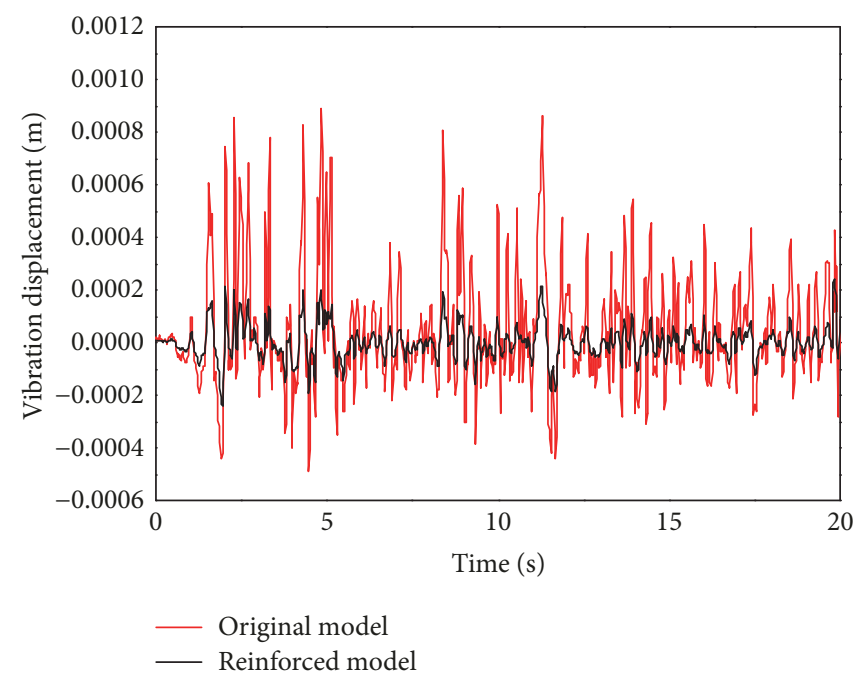

(d) Point 4

FIGURE 14: Dynamic responses of observed points on the reinforced masonry in time-domain.

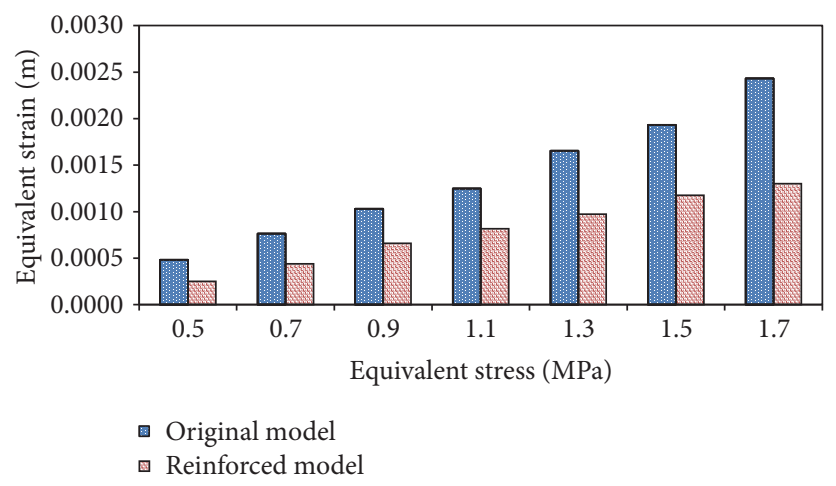

FIGURE 15: Equivalent strains of two kinds of masonry structures. 


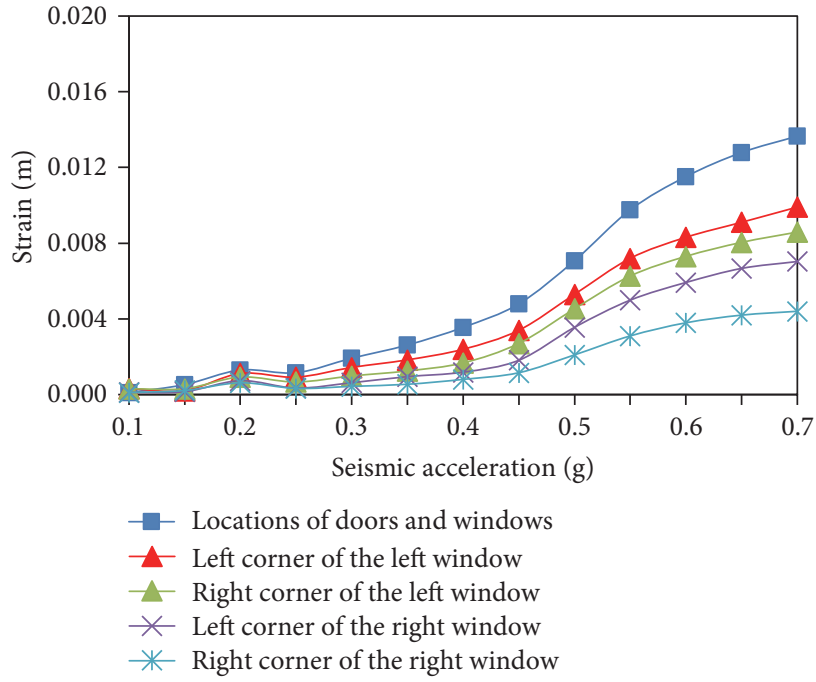

(a) Original model

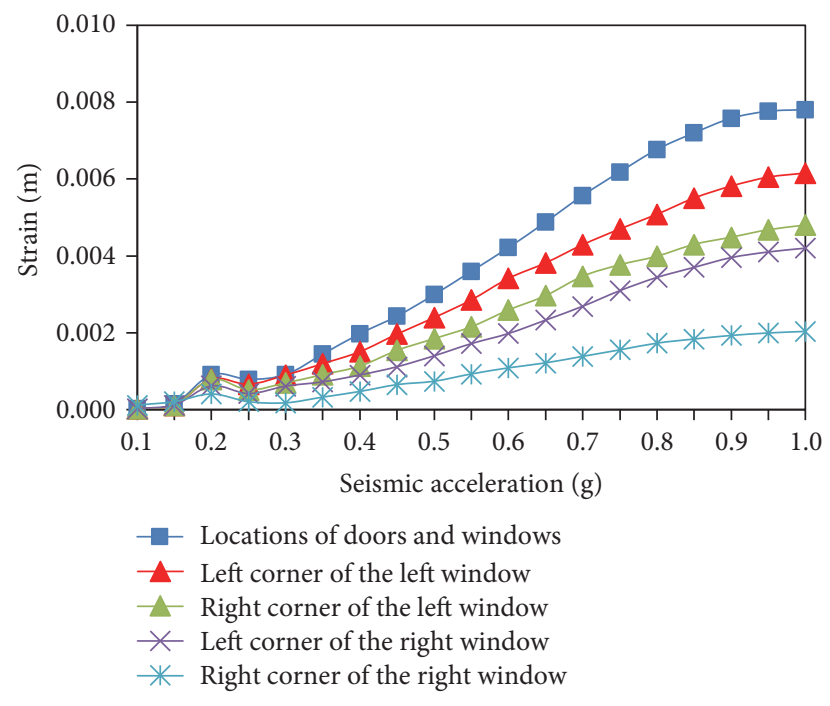

(b) Reinforced model

FIGURE 16: Strains of different positions on the masonry structure.

can effectively improve the antiseismic performance of the masonry structure.

\section{Data Availability}

The data used to support the findings of this study are available from the corresponding author upon request.

\section{Conflicts of Interest}

The authors declare that there are no conflicts of interest regarding the publication of this paper.

\section{References}

[1] L. Mollo and R. Greco, "Moisture measurements in masonry materials by time domain reflectometry," Journal of Materials in Civil Engineering, vol. 23, no. 4, pp. 441-444, 2011.

[2] M. Guizzardi, D. Derome, D. Mannes, R. Vonbank, and J. Carmeliet, "Electrical conductivity sensors for water penetration monitoring in building masonry materials," Materials and Structures/Materiaux et Constructions, vol. 49, no. 7, pp. 25352547, 2016.

[3] A. D’Ambrisi, L. Feo, and F. Focacci, "Experimental and analytical investigation on bond between carbon-FRCM materials and masonry," Composites Part B: Engineering, vol. 46, pp. 1520, 2013.

[4] S. A. Al-Sanea, M. F. Zedan, and S. N. Al-Hussain, "Effect of masonry material and surface absorptivity on critical thermal mass in insulated building walls," Applied Energy, vol. 102, pp. 1063-1070, 2013.

[5] B. Ghiassi, G. Marcari, D. V. Oliveira, and P. B. Lourenço, "Numerical analysis of bond behavior between masonry bricks and composite materials," Engineering Structures, vol. 43, pp. 210-220, 2012.

[6] T. Suzuki, H. Choi, Y. Sanada et al., "Experimental evaluation of the in-plane behaviour of masonry wall infilled RC frames,"
Bulletin of Earthquake Engineering, vol. 15, no. 10, pp. 42454267, 2017.

[7] L. Redmond, P. Ezzatfar, R. Des Roches, A. Stavridis, G. Ozcebe, and O. Kurc, "Finite element modeling of a reinforced concrete frame with masonry infill and mesh reinforced mortar subjected to earthquake loading," Earthquake Spectra, vol. 32, no. 1, pp. 393-414, 2016.

[8] H. Alwashali, Y. Torihata, K. Jin, and M. Maeda, "Experimental observations on the in-plane behaviour of masonry wall infilled RC frames; focusing on deformation limits and backbone curve," Bulletin of Earthquake Engineering, pp. 1-25, 2017.

[9] S. Nayak and S. C. Dutta, "Failure of masonry structures in earthquake: A few simple cost effective techniques as possible solutions," Engineering Structures, vol. 106, pp. 53-67, 2016.

[10] K. M. Dolatshahi and A. J. Aref, "Multi-directional response of unreinforced masonry walls: experimental and computational investigations," Earthquake Engineering \& Structural Dynamics, vol. 45, no. 9, pp. 1427-1449, 2016.

[11] S. Zheng, Y. Yang, and H. T. Zhao, "Experimental study on aseismic behavior of masonry building with frame-shear wall structure at lower stories," China Civil Engineering Journal, vol. 37 , no. 5, pp. 23-31, 2004

[12] H. G. Jia, H. L. Zhou, and X. Z. Yuan, "Study on characteristics and mechanism of seismic damage for walls of rural selfbuilt masonry house," Earthquake Resistant Engineering and Retrofitting, vol. 33, no. 3, pp. 127-132, 2011.

[13] S. Liu and L. P. Tong, "Analysis of crack development of bottom frame masonry structure under rare earthquake," Structural Engineers, vol. 30, no. 5, pp. 102-109, 2014.

[14] D. Y. Liang, X. Guo, Z. J. Jiang, and Y. Jiang, "Seismic behaviors of bottom-business multi-story masonry structure with winged columns," China Earthquake Engineering, vol. 39, no. 4, pp. 623631, 2017.

[15] H. Liu, Z. Ni, and J. Ou, "Simulation analysis of the collapse response of masonry structures subjected to strong ground motion," Earthquake Engineering and Engineering Vibration, vol. 28, no. 5, pp. 38-42, 2008. 
[16] A. Penna, S. Lagomarsino, and A. Galasco, "A nonlinear macroelement model for the seismic analysis of masonry buildings," Earthquake Engineering \& Structural Dynamics, vol. 43, no. 2, pp. 159-179, 2014.

[17] M. Betti, L. Galano, and A. Vignoli, "Comparative analysis on the seismic behaviour of unreinforced masonry buildings with flexible diaphragms," Engineering Structures, vol. 61, pp. 195208, 2014.

[18] F. H. Dong, C. H. Lou, Y. Liu, and B. J. Sun, "Numerical analysis on dynamic responses of single-storey buildings under seismic effects," Journal of Vibroengineering, vol. 19, no. 5, pp. 3581-3598, 2017.

[19] F. Y. Lou, T. B. Sun, X. Zhang, and H. F. Chen, “The collapse simulation of single-story masonry subjected to seismic ground motion," Earthquake Engineering and Engineering Dynamics, vol. 1, no. 2, pp. 71-77, 2015.

[20] Y. Cai, C. Shi, C. Ma, and T. Bao, "Study of the masonry shear strength under shear-compression action," Journal of Building Structures, vol. 25, no. 5, pp. 118-123, 2004.

[21] L. B. Zhu and Z. X. Dong, Nonlinear Analysis of Reinforced Concrete, Tongji University Press, Shanghai, 1985.

[22] Z. Y. Zhuang and C. K. Huang, "Experimental study on mechanical properties of model masonry," Building Structure, vol. 23, no. 2, pp. 22-25, 1997.

[23] V. Turnserk and F. Cacovic, "Some experimental results on the strength of brick masonry," in Proceedings of the SIBMAC, 1971.

[24] K. Cui and T. Qin X, "Virtual reality research of the dynamic characteristics of soft soil under metro vibration loads based on BP neural networks," Neural Computing \& Applications, pp. 1233-1242, 2017.

[25] A. Mohebkhah, A. A. Tasnimi, and H. A. Moghadam, "Nonlinear analysis of masonry-infilled steel frames with openings using discrete element method," Journal of Constructional Steel Research, vol. 64, no. 12, pp. 1463-1472, 2008.

[26] A. Yang, Y. Han, Y. Pan, H. Xing, and J. Li, "Optimum surface roughness prediction for titanium alloy by adopting response surface methodology," Results in Physics, vol. 7, pp. 1046-1050, 2017.

[27] A. Cecchi, G. Milani, and A. Tralli, "Validation of analytical multiparameter homogenization models for out-of-plane loaded masonry walls by means of the finite element method," Journal of Engineering Mechanics, vol. 131, no. 2, pp. 185-198, 2005.

[28] K. Cui, W.-H. Yang, and H.-Y. Gou, "Experimental research and finite element analysis on the dynamic characteristics of concrete steel bridges with multi-cracks," Journal of Vibroengineering, vol. 19, no. 6, pp. 4198-4209, 2017.

[29] Y.-L. Chung, T. Nagae, T. Hitaka, and M. Nakashima, "Seismic resistance capacity of high-rise buildings subjected to longperiod ground motions: E-defense shaking table test," Journal of Structural Engineering, vol. 136, no. 6, pp. 637-644, 2010.

[30] H. R. Tabatabaiefar, B. Fatahi, and B. Samali, "Seismic behavior of building frames considering dynamic soil-structure interaction," International Journal of Geomechanics, vol. 13, no. 4, pp. 409-420, 2013.

[31] M. R. Kianoush and A. R. Ghaemmaghami, "The effect of earthquake frequency content on the seismic behavior of concrete rectangular liquid tanks using the finite element method incorporating soil-structure interaction," Engineering Structures, vol. 33, no. 7, pp. 2186-2200, 2011.
[32] P. Memarzadeh, M. M. Saadatpour, and M. Azhari, "Nonlinear dynamic response and ductility requirements of a typical steel plate shear wall subjected to el centro earthquake," Iranian Journal of Science \& Technology, vol. 34, no. 4, pp. 371-384, 2010.

[33] F.-G. Fan and G. Ahmadi, "Nonstationary Kanai-Tajimi models for El Centro 1940 and Mexico City 1985 earthquakes," Probabilistic Engineering Mechanics, vol. 5, no. 4, pp. 171-181, 1990.

[34] F.-E. Udwadia and M.-D. Trifunac, "Comparison of earthquake and micro tremor ground motion in El Centro, California," Bulletin of the Seismological Society of America, vol. 63, no. 4, pp. 1227-1253, 1973. 


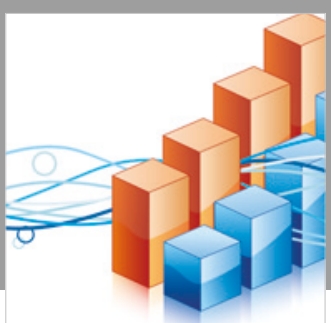

Advances in

Operations Research

\section{-n-m}
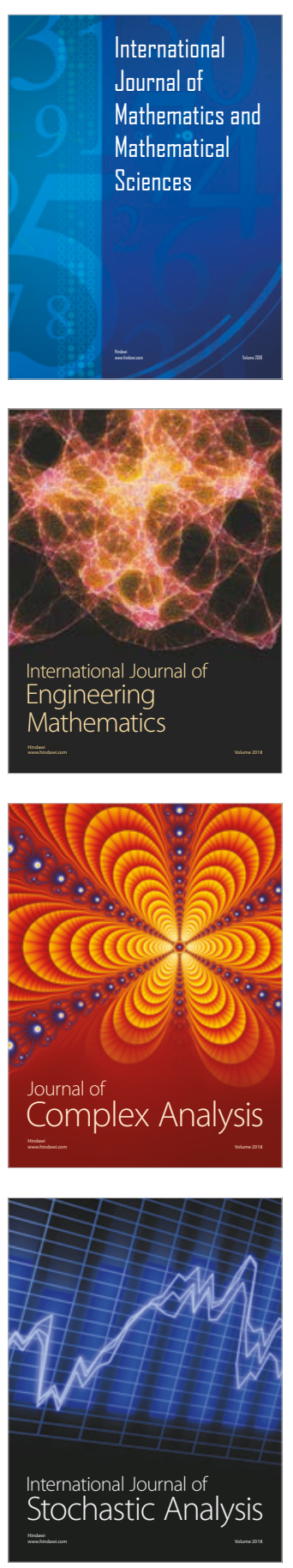
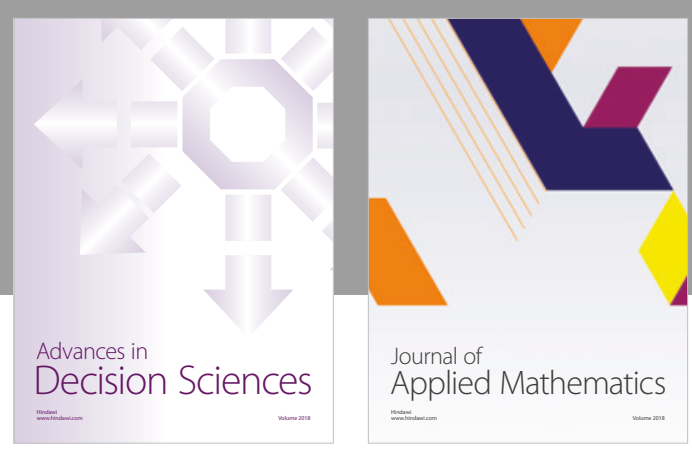

Journal of

Applied Mathematics
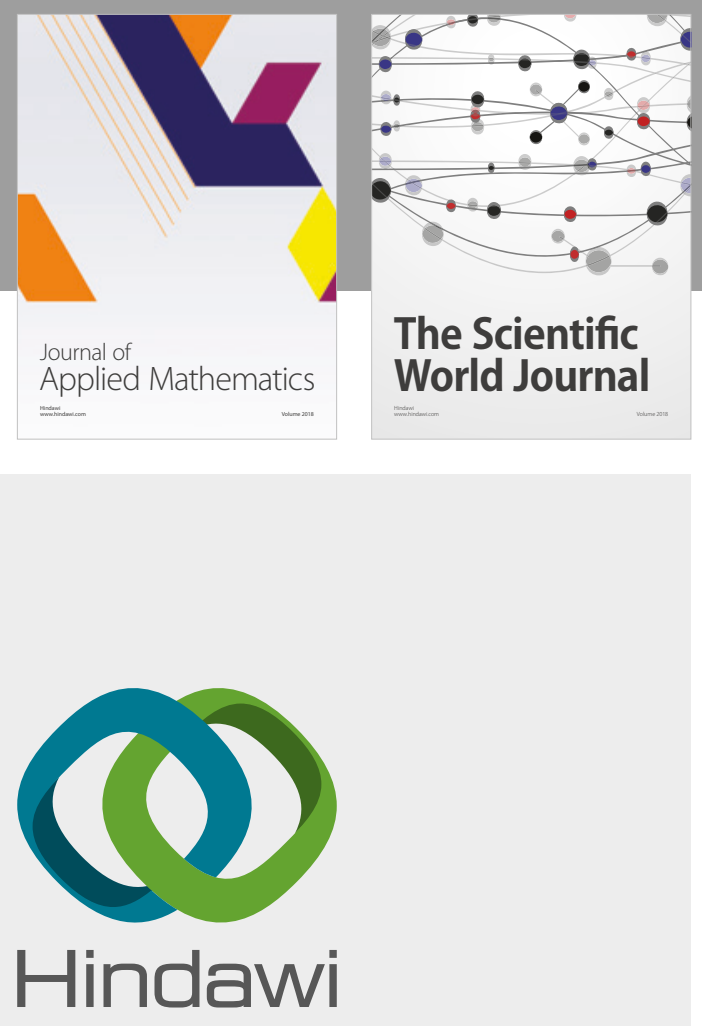

Submit your manuscripts at

www.hindawi.com

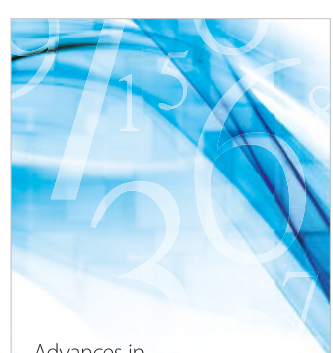

Advances in
Numerical Analysis
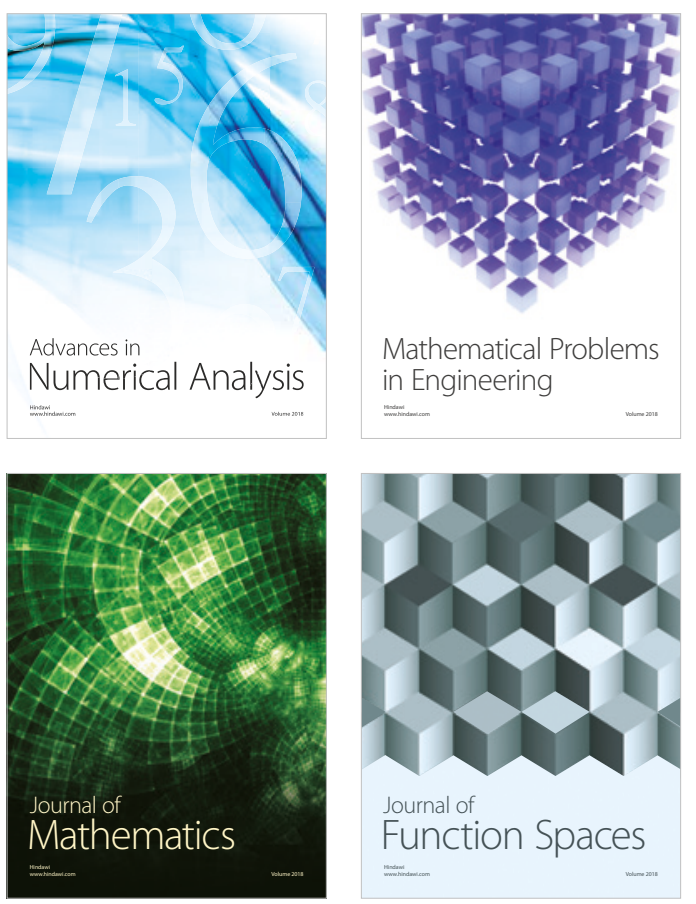

Mathematical Problems in Engineering

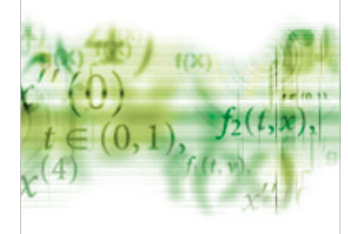

International Journal of

Differential Equations

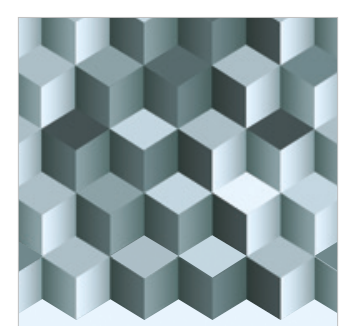

Journal of

Function Spaces
The Scientific

World Journal

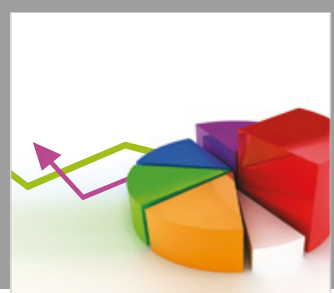

Journal of

Probability and Statistics
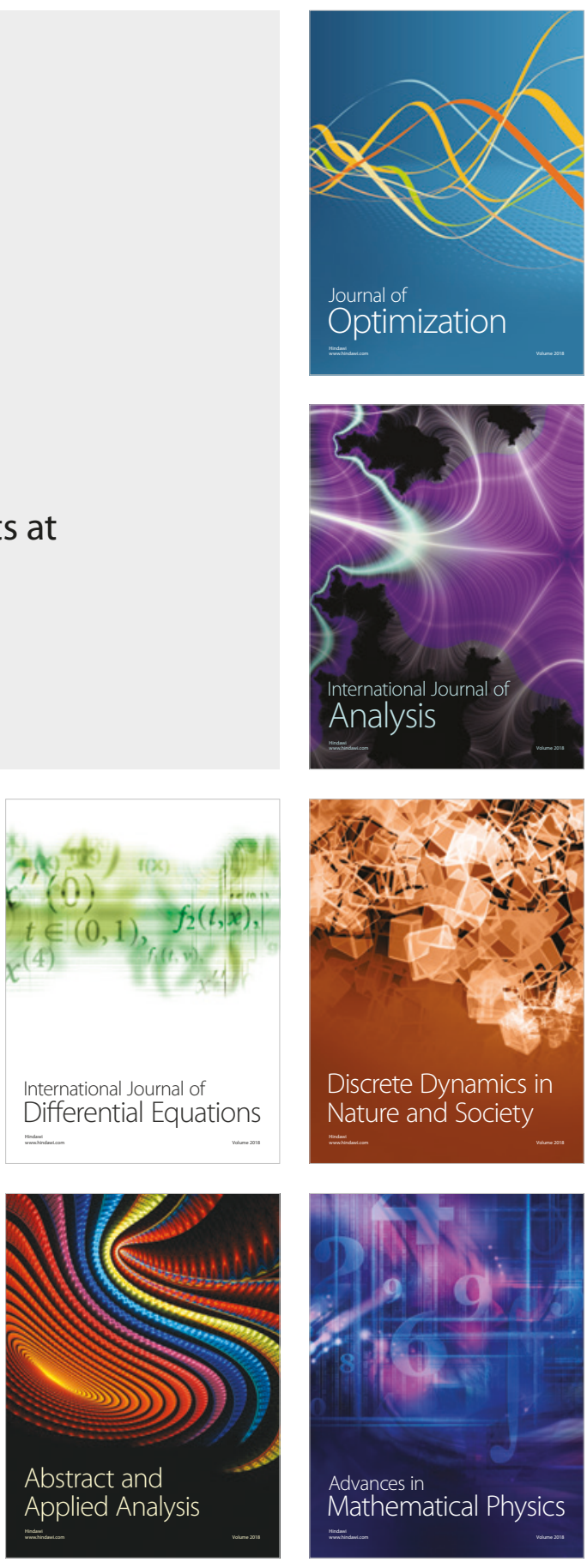